\title{
Effect of faying surfaces and characterization of aluminium AA6063-steel AISI304L Dissimilar joints fabricated by friction welding with Hemispherical Bowl, and Threaded Faying Surfaces
}

Senthil Murugan Subramanian ( $\sim$ gctsegan@gmail.com )

Mepco Schlenk Engineering College https://orcid.org/0000-0002-4920-6371

Sathiya Paulraj

Mepco Schlenk Engineering College

Noorul Haq Abdul Haq

Mepco Schlenk Engineering College

\section{Research Article}

Keywords: Hemispherical Bowl, Threaded, Friction Welding, Dissimilar Joint, Joint Efficiency, Faying Surface.

Posted Date: June 1st, 2021

DOI: https://doi.org/10.21203/rs.3.rs-348694/v1

License: (c) (1) This work is licensed under a Creative Commons Attribution 4.0 International License.

Read Full License 


\section{Abstract}

This work describes the effect of newly introduced faying surfaces on the microstructure and the mechanical properties of dissimilar weld joints of AA6063 and AISI304L alloys that fabricated through the rotary friction welding process (RFW). The experiments were done as six different experimental methods ('A' to ' $F$ ') at $1300 \mathrm{rpm}$ rotation, $18 \mathrm{MPa}$ friction pressure (FP), $24 \mathrm{MPa}$ upset pressure (UP) and 5 sec friction time (FT) with the faying surfaces of hemispherical bowl and thread of $1 \mathrm{~mm}$ pitch on the weld specimens. The fabricated joints and the weld zones were characterized by macro and micro-study, Energy Dispersive X-ray Spectroscopy (EDS) spectrums, tensile properties, Vickers microhardness, impact toughness and fractography. The results showed that these faying surface modifications strengthen the bonding between the weld specimens and influences the performance of the joints. The hemispherical bowl showed better results than the threaded surfaces. Axial shortenings were within the acceptable limit in the range of 20-27 mm. Macro and microstructural studies showed the defect-free weld joints and the strong bonding between AA6063 and AISI304L alloys. The hemispherical faying surface on AISI304L alloy formed a U-shaped weld interface (WI) in the dissimilar joints. EDS proved the formation of the Fe-Al intermetallic and the element ' $O$ ' at weld zone. The joint efficiency for all the methods was around $\geq$ $100 \%$. Maximum tensile strength was recorded as $238 \mathrm{MPa}$ for method ' $\mathrm{F}$ '. The threaded surface showed good hardness property nearby WI and method 'A' yielded maximum impact toughness for the joint.

\section{Introduction}

As the different chemical compositions and materials properties, joining of stainless steel with aluminium is difficult by fusion welding processes [1]. Friction welding (FW), a non-fusion joining, can be used for joining ferrous-nonferrous dissimilar metals. In this study, RFW was used for joining AA6063 and AISI304L dissimilar alloys with the contacting surface modifications on the weld specimen. The bonding mechanism between steel to aluminium relies on the diffusion of metal atoms at the interface. FW is an eco-friendly solid-state joining process, which means the welding takes place below its melting point [2]. In FW, a joint is made through frictional heating by the sliding action between the two faying surfaces of the weld specimens held together under pressure. In FW, the frictional force is the mechanical energy and the heat generated is the thermal energy. The soft material is expelled out as a flash under heat and pressure [3]. The FP is required to give the axial movement which is one of the main factors affecting the weld strength. The UP is for the consolidation of the weld [4]. The contact pressure of the interface centre is higher than that of the edge and the temperature in the core becomes greater than the perimeter of the weld in FW. The dissimilar metal welds are widely used in boiler, oil refining industries. Many dissimilar combinations have been successfully welded, including steel to aluminium, steel to copper base alloys, stainless steel to nickel-base alloys, etc. There are numerous applications in which welds are made from metals of different compositions considering different properties required from different parts of the same weldment. This fetches the need for joining dissimilar metals in industries. The dissimilarity in the melting point of dissimilar metals to be joined must be considered in the FW since one metal will be in the molten stage long before the other when subjected to the same heat amount. Zinda et al. ${ }^{[5]}$ researched 
the frictional joining between aluminium (5A33) and magnesium (AZ31B) alloys and reported that the tensile strength increased with the increase of the FT $(5 \mathrm{sec})$ and the formed intermetallics improved the hardness of joints. The effect of FT was identified through their research. Kimura et al. ${ }^{[6]}$ joined Al.6063 and SS304 steel dissimilar alloys through the FW process and achieved $100 \%$ efficiency with sound weld joints. Radosław Winiczenko ${ }^{[7]}$ achieved $87 \%$ efficiency when joining AISI1020 with A536 dissimilar alloys and found the diffusion of carbon from iron to steel through EDS. It is informed through their research that a small amount of the base metal was heated and that molten metal was thrown from the joint during the FW, therefore, the intermetallic material was kept to a very minimum. The heat-affected zones (HAZ) are also minimal and narrow [8]. A successful weld between dissimilar metals is one, that is as strong as the weaker of the two metals being joined and research stated that the quality of weld surface joint can be checked and the crack can be found with image segmentation technique as the coefficient of friction between the metals during friction welding is prominent [9]. Also, the problem of joining dissimilar metals depends on the quality of the transition zone in the joint and the intermetallic phases that occurred in this transition zone. For example, a discontinuous layer that formed at the joint interface during the friction welding between the pure Al./Fe metals caused the failure almost at their joints when the load applied [10]. Similarly, Gawhar and Sherko ${ }^{[11]}$ joined the SS316L steel to AISI1045 steel and found the failure nearby the thermo-mechanically affected zone (TMAZ), also the author informed that the forge pressure is responsible to increase the hardness. The dissimilar joints are made successful only if there is mutual solubility of the two metals. If there is little or no solubility between the two different metals to be joined then the weld joint will not be successful. Sometimes, it is necessary to use a third metal that is soluble with each metal to produce a successful joint. The transition zone has to be examined to determine its crack sensitivity, strength and susceptibility to corrosion [12]. Thermal expansion of metals plays a vital role in the failures of the dissimilar weld by developing high stress at the weld interface [13]. If the coefficient of thermal expansion of both materials is widely different, there would be internal stresses set up in the intermetallic zone during any temperature change of the weldment. If the intermetallic zone is brittle it may lead to having weld failure soon. Prasanthi et al. ${ }^{[14]}$ successfully welded mild steel with titanium rod of $\$ 10 \mathrm{~mm} \times 100 \mathrm{~mm}$ size using the FW process. Through their study, they confirmed the formation of fine Fe-Ti intermetallic phase at the weld interface and the hardness of $350 \mathrm{VHN}$ was obtained at the interface. Prashanth et al. ${ }^{[15]}$ did FW of Al-12Si metal generated by selective laser melting process. The results showed the improvement in ductility whereas the drop in hardness in weld interface compared to the base metal. Marlon and Alexandre ${ }^{[16]}$ studied the influence of the surface contact geometry (faying modifications) of joining Al.6351/1020 steel through FW and accepted that the geometry on the contact pin would influence the mechanical properties. Senthil et al. ${ }^{[17]}$ did the experiments of joining AISI304 and AA6063 with tapered faying modification on the AISI304 side and proved the effect of faying surface on the efficiency of the weld joint and the improvement in their joint properties through their research. A novelty of this work is to newly introduce the hemispherical bowl and threaded faying surfaces on the weld metals for the friction welding of dissimilar alloys. In this work, dissimilar joints of aluminium AA6063 and stainless steel AISI304L are fabricated with different faying surfaces (as mentioned here as Experimental methods ' $A$ ' to ' $F$ ') and the 
performance of the weld joints is evaluated through the different characterisation techniques. This study also aims to identify the welding feasibility and the joint efficiency of the different experimental methods tried on these base metals through rotary friction welding machine.

\section{Materials And Methods}

\subsection{Materials}

The materials used in this study consist of aluminium AA6063 (T6 tempered) and stainless steel AISI304L alloys. These dissimilar combinations are used in cryogenic applications [18]. The chemical elements present in the materials and their values in the mass fraction are given in Table 1. The chemical compositions of the materials were confirmed with optical emission spectrography (OES) as per the standard ASTM E1251. The materials were in the form of a cylindrical rod for the welding experiments. AA6063 is a soft material whereas AISI304L having a low percentage of carbon is a hard material. The joining of both materials is a mandatory one in structural applications. The melting point of AISI304L alloy is almost two times greater than AA6063 alloy, so a huge variation is there in the performance while welding. AISI304L is widely used in many applications due to excellent properties [19] and it is also becoming popular for the combination with other material. The properties of weld metals are reported in Table 2.

Table 1: Chemical composition of base metals

\begin{tabular}{|c|c|c|c|c|c|c|c|c|c|}
\hline \multicolumn{10}{|c|}{ Material: AISI304L alloy } \\
\hline Elements & $\mathrm{Cr}$ & $\mathrm{Ni}$ & $\mathrm{Mn}$ & $\mathrm{Si}$ & \multicolumn{2}{|l|}{$\mathrm{P}$} & $\mathrm{C}$ & $\mathrm{S}$ & \multirow[t]{3}{*}{$\mathrm{Fe}$} \\
\hline Weight & 19.15 & 8.09 & 1.43 & 0.38 & \multirow{2}{*}{\multicolumn{2}{|c|}{0.034}} & 0.023 & \multirow[t]{2}{*}{0.009} & \\
\hline$\%$ & balance & & & & & & & & \\
\hline \multicolumn{10}{|c|}{ Material: AA6063 alloy } \\
\hline Elements & $\mathrm{Al}$ & $\mathrm{Si}$ & $\mathrm{Mg}$ & $\mathrm{Fe}$ & $\mathrm{Zn}$ & $\mathrm{Mn}$ & $\mathrm{Cu}$ & $\mathrm{Ti}$ & $\mathrm{Cr}$ \\
\hline Weight & 98.58 & 0.5 & 0.41 & 0.26 & 0.061 & 0.044 & 0.029 & 0.02 & 0.009 \\
\hline$\%$ & & & & & & & & & \\
\hline
\end{tabular}

Table 2: Properties of base metal of the study (at room temperature)

\begin{tabular}{lcc}
\hline Properties & AA6063 & AISI304L \\
\hline Density $\left(\mathrm{g} / \mathrm{cm}^{3}\right.$ ) & 2.7 & 8.0 \\
Tensile strength (MPa) & 205 & 515 \\
Elongation (\%) & 10 & 45 \\
Melting point $\left({ }^{\circ} \mathrm{C}\right)$ & 655 & 1450 \\
Vickers hardness $(\mathrm{Hv})$ & 80 & 200 \\
\hline
\end{tabular}




\subsection{Methods}

The experiments were carried out by a direct drive rotary friction welding machine (model: KAKA, German). Initially, the faying surfaces of the weld specimen of having $\phi 12 \mathrm{~mm}$ diameter and $100 \mathrm{~mm}$ length rods were modified with three different kinds of faying surfaces on weld specimens like a hemispherical bowl (Figures 1(a,d)), flat surface (Figures 1(b, e)) and thread of $1 \mathrm{~mm}$ pitch for $10 \mathrm{~mm}$ long along with a length of faying surfaces (Figures $1(c, f)$ ). The cleanliness of the weld specimen is necessary since the contaminants like grease, dust and oil may reduce the quality of joints. According to the experimental description given in Figure 2, the joints were made with different surface modifications. A schematic view of the welding process followed in this study is shown in Figure 3 . The joints were prepared at $1300 \mathrm{rpm}, 18 \mathrm{FP}, 24 \mathrm{UP}, 5 \mathrm{sec}$. FT, 3-sec upset time (UT) and $3 \mathrm{~mm} / \mathrm{sec}$ feed rate. The welding parameters were selected based on the trial and error methods and the literature survey. The recommended parameter values were chosen for this study. The upset pressure is higher than that of friction pressure for its better efficiency. After the fabrication of dissimilar welds, the samples were prepared from the welds as per ASTM standard for characterisation and mechanical testing. The ASTM E8 standard (Figure 4(a)) and ASTM E23 standard (Figure 4(b)) were followed for tensile and impact testing respectively. The macrostructure and microstructure of joints were taken with the help of an optical microscope (OM) and scanning electron microscope (SEM). The Energy dispersive spectroscopy (EDS) analysis was also done on the weld zones. SEM (Model: Geminis SEM 300, Carlzeiss) affords the images at $15 \mathrm{kV}$ with the apertures range: of 10 to $300 \mu \mathrm{m}$. The hardness of the weld zone of each experimental methods was measured using a Vickers hardness tester (Model: INNOVATEST) of 300-gram load and 15 seconds dwell time. The tensile testing was performed with a universal testing machine (Model: MTS $1000 \mathrm{kN}-\mathrm{INSIGHT}$ ). For impact testing, the testing was done with a Charpy machine (Model: MTS (SANZ)-ZBC2452) at room temperature. The impact machine has the maximum capability of 450 kJ impacting energy. The testing was performed with the parameters like $15 \mathrm{~N}$-m striker force moment, $5.24 \mathrm{~m} / \mathrm{s}$ impact speed and $150^{\circ}$ raising angle. An indenter will move on this scale when a pendulum is allowed from its horizontal static position to impact the V-notched specimen. There is a stand at the bottom of the machine where the $V$-notched specimen is supported as a beam in a horizontal position. In addition to that, the fracture analysis was also done on the tensile and impact tested samples using SEM equipment.

\section{Results And Discussion}

\subsection{Observation and Axial Shortening}

The friction welded dissimilar welds are shown in Figure 5(a) along with its weld joint images (Figure $5(b)-5(f)$ ) which were noted after the flash removal. From the weld flash shown in figure 5(a), it is observed that the faying surface modifications may also show their effect on the metal flash expelled during the application of frictional force during the friction welding. The experiment with a hemispherical 
bowl shape on AISI304L (Methods ' $E$ ', ' $F$ ') shows the maximum volume of flash expelled during the joining. But, the hemispherical bowl shape on AA6063 (Method ' $D$ ') gives not much flash volume in the weld joint as compared to methods ' $E$ ' and 'F'. From figure 5(a), it is observed that the axial shortening in the AA6063 side is much more than that of the AISI304L side. As the melting point of AA6063 is lower than that of AISI304L, the flash may contain aluminium at the interface. The experimental method ' $A$ ' showed a fine weld interface (Figure 5(b)). In the experimental method ' $B$ ', the penetration of threaded AISI304L alloy is about 3 pitches into AA6063 alloy (Figure 5(c)). But, in method ' $C$ ', the penetration of threaded AISI304L alloy is about 5 pitches into AA6063 alloy as the threaded faying surface of AA6063 stimulates the bonding between AISI304L and AA6063 specimens during FW (Figure 5(d)). The weld joints of methods ' $D$ ', 'E' and ' $F$ ' are shown in figures 5(e), 5(f) and 5(g) respectively. The specimens were bisected with an EDM machine to analyse the weld interface. The weld interfaces of all joints are shown in figure 6(a-f). The EDM cutting efficiency was measured in terms of the surface roughness between $0.18 \mu \mathrm{m}-0.44 \mu \mathrm{m}$. In figure $6(\mathrm{a})$, a threaded portion of the AA6063 side is shown. Figure $6(\mathrm{~b})$ shows the penetration of threaded stainless steel into the aluminium alloy. The thread on the AA6063 side (joining method ' $C$ ') caused to have more insertion of threaded AISI304L alloy into the AA6063 specimen as shown in figure 6(c). The joint with the method ' $D$ ' had the straight interface as in figure $6(d)$ even though the AA6063 side has a hemispherical bowl during FW. The U-shaped weld interfaces were seen in figures 6(e) \& 6(f) for methods 'E' \& 'F' respectively. But the AISI304L alloy with hemispherical bowl only creates the U-shape weld interface. Figure 7 shows the axial shortening of different weld joints observed during FW. The maximum shortening of $26.5 \mathrm{~mm}$ was regarded for method ' $\mathrm{E}$ ' as the effect of the hemispherical surface of the AISI304L side.

\subsection{Macrograph, Microstructure and EDS study}

\subsubsection{Macrographs of Weld Zones}

The weld zones of friction welded dissimilar joints were characterized by macrographs, optical microstructures (OM) \& Scanning Electron Microscope (SEM) images, and point \& line EDS spectrum with colour mapping. The characterization results are presented here. Figure $8(a-f)$ shows the macro images of welded joints with different faying surface modifications under 10X magnification. The images were taken using a stero microscope following the ASTM E340-15 standard. But in some cases, the etchant "Aqua regia" was used for identifying the defects if any and the clear weld flow on the specimen. The images reveal the complete fusion between the weld specimen and the base metal. No defects were found in the weld zone. In figure 8(a), the edges of the threaded AA6063 and the penetration of AISI304L into AA6063 were seen. The weld interface was showing a good bonding between the dissimilar alloys. Image 8(b) shows the two pitches of AISI304L penetration into the AA6063 alloy and incomplete bonding on one of its edges between AA6063 and AISI304L. In image 8(c), in one of the weld joint edges, the three pitches of the AISI304L specimen were having unsatisfied contact with the pitches of AA6063 alloy but the other edge shows the good bonding between base alloys. From the images, it was understood that the threading was stimulating the bonding between the base metals. Image 8(d) shows the macro image of the weld joint fabricated with method ' $D$ ' and the weld interface is good with no defects. Though the 
AA6063 specimen was having hemispherical bowl faying surfaces, it was not seen in image 8(d). This is due to the rotational impact of the AISI304L specimen with $18 \mathrm{MPa}$ FP. Though there was an incomplete bonding found on one of the weld joint edges of the welded sample joint fabricated by method 'E' (image $8(e))$, the WI is strong and shows good results. Here both edges of the weld interface were not in a straight line. Image $8(f)$ shows the good weld joint and the perfect complete boding with no defects.

\subsubsection{Optical Microstructures and Width Measurement of Weld Zones}

The weld zones were characterized by an optical microscope. Figure 9 (a to r), shows the optical microstructures of the weld joints (base metals and weld regions) of all experimental methods taken using a metallurgical microscope, Dewinter optical tech following ASTM E3-11 (RA 17) standard. Under the 200X magnification, microstructures show very good bonding between the base metals. The weld zone of joints consists of a WI, TMAZ [20], and HAZ. The widths of these zones were measured and the graph was plotted with their values as shown in figure 10. To find the clear microstructures, the etchants used for AA6063 and AISI304L were Kroll's and Glyceregia respectively. From the microstructures' images, the AA6063 base metal shows fine Al-Si eutectic particles in a matrix of Al. solid solution. While the AISI304L structure shows fine twinned austenite grains with carbide precipitation. For method ' $A$ ' (figure 9(a)-9(c)), the width of WI was about $33 \mu \mathrm{m}$ and the HAZ \& TMAZ were observed nearby WI. The WI was narrow and grains nearby WI of base metals were modified due to the FP. Figure 9(d)-9(f), the width of WI was very narrow of $24 \mu \mathrm{m}$. The WI shows the wavy like format which might be due to the threaded faying surfaces on the AISI304L specimen. The HAZ was also regarded as $57 \mu \mathrm{m}$ and comparatively lower than method 'A'. From the images $9(\mathrm{~g})-9(\mathrm{i})$, a very narrow WI of $14 \mu \mathrm{m}$ is observed. The elongated and the refined grains were seen nearby WI. The narrow HAZ of $20 \mu \mathrm{m}$ size is also found here. Images $9(\mathrm{j})-9(\mathrm{I})$ show the structure of method ' $D$ '. From the images, the widths of WI, TMAZ, and HAZ were measured. A very narrow TMAZ of around 25-micron size was identified. The images $9(\mathrm{~m})-9(\mathrm{o})$ are of the weld joint with the joining method ' $E$ ' and the WI is seen. The narrow WI and TMAZ were identified with 22 and 11micron size respectively. The deformed and elongated grains were also seen in the images nearby WI. Images 9(p), 9(q) and 9(r) are showing the AA6063 bases, WI and AISI304L base structures respectively. Eutectic particles are identified on the AA6063 base side and austenitic grains with carbide precipitates are identified on the AISI304L side. The HAZ width maximum of 140 microns was measured and the WI of the strong joint was observed as 37 microns. In figure 10, it is shown that the width of the TMAZ is smaller than $\mathrm{HAZ}$ and the joining method ' $\mathrm{C}$ ' shows the minimum width compared to others.

\subsubsection{SEM Images of Weld Joints}

The SEM images of the weld interface of the various dissimilar joints for the experimental methods ' $\mathrm{A}$ ' to ' $F$ ' are given in figures 11 (a) to 11(f) respectively. The structures (Figure 11) were taken at the central core and middle of the weld interface (Figure 8) with 200 micron scale. In the SEM images, the weld joint lines were mentioned as ' $W I$ ' which means dissimilar weld interface. The SEM images show no defects along the WI line. In image 11(a), the diffused aluminium is seen nearby WI, which is due to the hard force given by AISI304L alloy during FW. So it is decided that the threaded face of AA6063 alloy stimulate the 
bonding between stainless steel and aluminium alloys weld specimens. In image 11(b), the thread-like WI is shown; it may be due to the threaded effect of the AISI304L specimen. But here no diffused AA6063 alloy is seen nearby WI. Figure 11(c) has some elongated grains nearby WI with no AA6063 alloy debris in WI and HAZ. Figure 11(d) has micron size elements in the weld zone with no defects. But in figure 11(e), the AA6063 side nearby WI got forced by the hemispherical bowl faying surface of AISI304L alloy during FW and then bonding was created between the weld specimens. This hemispherical faying surface created a thicker WI than that of the threaded faying surface. The diffusion of elements nearby WI on both sides is seen. Figure 11(f) shows the bonding between both hemispherical bowl faying surfaces of AA6063 and AISI304L weld specimens. Though the faying surface of AISI304L in method ' $F$ ' and the welding parameters are similar to the method ' $E$ ', the WI generated by method ' $F$ ' shown in image 11(f) seems to be different compared to image 11 (e) belonging to method ' $E$ '. This difference takes place mainly due to the faying surface of AA6063 part as in method ' $F$ '. From the SEM resuts, the thickness and the shape of the $\mathrm{Wl}$ and the weld zone property are changine depending on the faying surfaces of the weld specimens. It is inferred that the faying surface modifications can influence the bonding in weld boundary of the dissimilar joint.

\subsubsection{Line EDS Analysis on Weld Zone of Different Joints}

Energy-dispersive X-ray spectroscopy analysis like line elemental analysis, point analysis and colour mapping analysis was performed on the friction welded dissimilar joints to investigate the wt.\% of elements present and their distribution along the weld zone of the dissimilar joint on both AA6063 and AISI304L sides; besides, to find the phases that occur at the weld interface during the friction welding. Figure 12 (a-d6) shows the description of the line EDS analysis along the weld zone area of the fabricated joints. In the figure, the FE-SEM images of weld regions where the EDS analysis was done on the weld joint along weld zone are shown as images in figure 12 like (a, a1, a2), (b, b1, b2), (c, c1, c2, c5, c6), and $(d, d 1, d 2)$ for the experimental methods ' $A$ ', 'C', ' $E$ ', and ' $F$ ' respectively. For methods ' $B$ ' and ' $D$ ', the focusing was not good on the weld joint by the equipment during scanning so it could not be able to take line EDS report for the joints fabricated through methods ' $B$ ' and ' $D$ ' and the results are not presented in this paper. In image 12(a), the line EDS was analysed along the region ' $A B$ ' and ' $C D$ ' and the results are presented. Figure 12 (a3) \& (a4) is the element distribution along 'AB' and 'CD' regions respectively. Similarly, the spectra of elements that present at 'AB' and ' $C D$ ' are reported in figure 12 (a5), (a6) respectively. For ' $A B$ ', the total length analysed was $700 \mu \mathrm{m}$ along the weld zone, in which the aluminium present up to $450 \mu \mathrm{m}$ and then the 'Fe' contents are shown. In the region between 400-500 $\mu \mathrm{m}$ length, the elements $\mathrm{O}, \mathrm{Si}, \mathrm{Al}, \mathrm{Fe}, \mathrm{Ni}, \mathrm{C}$ and $\mathrm{Cr}$ are presents. But the ' $\mathrm{Cr}$ ' is present in both the $\mathrm{AA6063}$ and $\mathrm{AISI} 304 \mathrm{~L}$ sides. From the spectra of method ' $A$ ', the wt. \% of elements is known. The element ' $O$ ' is seen around 5-6 wt. \% along the region $A B, C D$. In image 12(b, b1, b2), the expelled AA6063 content during FW is seen. The line EDS analysis (figure 12 (b3 \& b4)) shows the elements distributions along the region 'EF' and 'GH' is given in different colours. Very few traces of ' $\mathrm{Ag}$ ' and ' $\mathrm{Mg}$ ' elements were seen and according to line spectrum images (figure 12 (b5 \& b6)), the 'Al' content is a little bit higher than 'Fe' content. The image 12 (c) is belonging to method ' $E$ ' which was having a hemispherical bowl shape on its AISI304L specimen during FW. Due to the hemispherical shape of AISI304L, the U-shaped strong weld interface is shown in 
image 12(c). Here, the weld boundaries (IJ, KL-Figure 12(c1, c2)) and HAZs of AISI304L (MN- figure 12(c7)) and AA6063 (OP- figure 12(c8)) were analysed. The line spectra by the analysis are present in figure 12 (c5, c6, c11 and c12). The presence of iron (Fe) content is much higher in the IJ region (image $c 2, c 4$ ) than in the $K L$ region (image $c 1, c 3$ ). The element distribution phases present along HAZ are shown in images 12(c9-c12). Image $12(d, d 1, d 2)$ shows the FESEM images of the weld interface of experimental method ' $F$ '. As usual, images $12(d 3, d 4)$ and $12(d 5, d 6)$ are showing the line spectra of the element distribution along the weld region and the wt. \% of elements available at weld zones, respectively. It shows the elements like ' $O$ ' in the weld interface and the diffusion of ' $F$ ' from AISI304L to the AA6063 region across the weld boundary. Thus, EDS analysis is worth to know the major elements (wt.\%) and their distribution in weld joint.

\subsubsection{Point EDS Analysis on Weld Zone of Different Joints}

Figure 13(a-f4) shows the point EDS analysis which is different from the line spectrum. Here, the point spectrum was taken at the regions like HAZs of AISI304L and AA6063 sides and WI. The points where the point EDS analysed are shown in the SEM images of Figure 13 (a to $f$ ) for the experimental methods ' $A$ ' to 'F' respectively. The spectra images 'a1', 'a2' and 'a3' of Figure 13 are representing for the regions WI, HAZ of AISI304L and HAZ of AA6063 respectively of the joint that shown in image 13(a). From the spectra, it is observed that the method ' $A$ ' joint has $\mathrm{Fe}, \mathrm{Cr}, \mathrm{Ni}, \mathrm{C}$ majorly in the weld interface (point ' $A$ ' in image 13(a)) while the HAZ of AA6063 side (point ' $C$ ' in the image 13(a)) showed the presence of Al, $O$ and $C$ only. But, the HAZ of AISI304L (point ' $\mathrm{B}$ ' in image 13(a)) has Fe, $\mathrm{Cr}$, C etc. as shown in image 13(a2). Figure 13(b) is the SEM image of the joint by method ' $\mathrm{B}$ '. From image 13(b1), it is observed that the method ' $\mathrm{B}$ ' has majorly $\mathrm{Fe}, \mathrm{Cr}, \mathrm{Ni}$ and $\mathrm{C}$; but in the HAZ of AA6063 side (point ' $\mathrm{B}$ ' in image 13(b)), the 'Fe' presence of 5.3 $\%$ is shown, which proves the element transfer of iron from AISI304L side to AA6063 side crossing the weld boundary during FW. Similarly, the presence of ' $O$ ' is also recorded in image 13(b3). From image 13(b2), the chromium content of around $18 \%$ is proved along with $7.5 \% \mathrm{Ni}$ in the weld interface of the joint. It showed the improvement of corrosion resistance of the joint. Image 13(c) is the image of the experimental method ' $C$ '. The HAZ of AA6063 and AISI304L sides are shown in images 13(c1), 13(c2) respectively, and the weld interface elements shown in 13(c3). Through the point EDS analysis, it is known that the weld interface of method ' $D$ ' (Figure 13(d)) contained elements like Fe, Al in almost equal share, and $\mathrm{Ni}, \mathrm{Cr}$, and $\mathrm{O}$ etc. along with the few amount of ' $\mathrm{Ag}^{\prime}$ and 'Si' as shown in figure 13(d1). Furthermore, the HAZs on both side of joints and weld joint for the methods ' $E$ ' and ' $F$ ' were analysed and their elements in wt. \% are shown in figures 13(e1-e3) and 13(f1-f4) respectively.

\subsubsection{EDS Colour Mapping on Weld Zone}

The colour mapping and their EDS analysis for the joints fabricated by the methods A, B, C, E and F are denoted by Figures $14(\mathrm{a}-\mathrm{c}),(\mathrm{d}-\mathrm{f}),(\mathrm{g}-\mathrm{i}),(\mathrm{j}-\mathrm{I})$, and $(\mathrm{m}-\mathrm{o})$ respectively. For the joint ' $\mathrm{D}$ ', it could not be taken as the equipment focusing was not good on the specimen. It is helpful to distinguish the elements in the images shown by the different colours. Most of the joints have ' $O$ ' element in the weld interface ad the ' $O$ ' was entrapped at the weld interface during the friction welding. When the aluminium is in semi-solid 
state, it observed maximum of oxygen. From the colour images, the diffusion of 'Al' and 'Fe' across the boundary during FW is identified. The wt. \% of the elements is shown in the map spectrum and the developed weld zone including the dissimilar joint is shown in the SEM microstructures. The good bonding between the alloys is confirmed.

\subsection{Tensile Properties and Tensile Fracture Analysis}

The fabricated weld joints through the new experimental methods ' $A$ ' to ' $F$ ' were initially dropped from 1meter height for the preliminary qualifications to check their strength by the drop test [21]. Once the joints were passed in the drop test, then they have undergone mechanical testing. The welded dissimilar joints after the tensile testing are shown in figure 15 . The friction welding parameters determine the tensile strength of the joint [22]. In the figure, the plastic deformation and neck formation can be seen in the metal parts. All the breakage happed to the outside of the weld during the tensile testing. While welding, the aluminium at semi-solid state extruded at the interface and tied up with frictionally heated AISI304L metal faying surfaces due to the metal affinity property of both Al and Fe. Based on the mechanism, the metal bonding was formed with good strength. The method ' $E$ ' and ' $F$ ' (of hemispherical bowl faying surface on AISI304L specimen) showed much better neck formation compared to others. But the method ' $D$ ' was also having a hemispherical bowl on the AA6063 side, but it did not yield much better neck formation than that of what ' $E$ ' \& ' $F$ ' methods yield. From this statement, it is well known that the methods with hemispherical bowl faying surface on AISI304L were better than the hemispherical bowl on the AA6063 specimen. Like this, the methods with the threaded faying surfaces on the AISI304L side gave good results. Though the faying surface modifications on the AA6063 side did not give the results equal to the results of the joints with the faying surface modification on the AISI304L side, the threaded and hemispherical faying surfaces on the AA6063 side stimulate the bonding between AA6063 and AISI304L during FW. The tensile test results are reported in figure $16(\mathrm{a}-\mathrm{g})$. The maximum $238 \mathrm{MPa}$ tensile strength was recorded for the joint fabricated by method ' $F$ '. But the method ' $E$ ' also produced almost equal to the strength of method F's joint. Similarly, the yield strength was also noted and given in figure 16(a). All the experimental methods showed good strength compared to the AA6063 base metal. From the results, the hemispherical faying surface produced maximum strength than the threaded faying surface modifications. Figure 16(b) shows the elongation that occurred during tensile testing of the welded joints. Even though the strength is good; it showed low elongation on the joints except for method ' $E$ ' and ' $F$ '. Joining method ' $E$ ' had the maximum elongation (\%) with the value of $13 \%$ followed by method ' $F$ ' with $11 \%$. This elongation is higher than that of AA6063-T6 base metal (Table 2). The methods ' $A$ ' to ' $D$ ' may reduce the elongation and the plastic deformation on the joints in this work. Figures 16 (c) \& 16(d) have the relationship of tensile and yield strength because this relationship decides the elongation and the strain hardening behaviour of the joints. From Figure 16(c), the hemispherical faying modifications have a much better tensile to yield strength (TS/YS) ratio and a maximum of 1.4 for method ' $E$ '. If this ratio is higher it means that the ductility and strain hardening nature $[23,24]$ before the ultimate strength is higher for the joints. The TS and YS differences are also given in figure 16(d). Methods ' $A$ ' to ' $C$ ' show almost the same TS YS difference but method ' $E$ ' has a much better value. Figure 16(f) is the peak value during testing. The maximum value of $15 \mathrm{kN}$ was recorded for the methods ' $E$ ' and ' $F$ ', which means that 
a hard effort was given by the joints of methods ' $E$ ' and ' $F$ ' against the pulling load during the tensile test. It is mandatory to measure the weld joint efficiency to identify the effectiveness of the experimental welding methods and the quality of the joint considering the tensile strengths of both the joint and the soft base metal in the weld joint $[25,26]$. Here, the joint efficiency of the methods is calculated based on the ratio of tensile strength of the fabricated dissimilar joint to the tensile strength of the AA6063 base metal (Table 2). The experimental methods own almost equal or greater than $100 \%$ with a maximum of $116 \%$ for method ' $F$ ' followed by method ' $E$ ' with $115 \%$. It is a good sign of using these kind of experimental methods in industries. In this study, the shear yield strength is mathematically calculated from the yield strength of the joints as per Von Mises yield criterion following equation 1 [27] and the calculated shear values are in figure 16(g).

$$
\tau=(1 / \sqrt{ } 3) \sigma_{\mathrm{Y}}=0.577 \sigma_{\mathrm{Y}}
$$

where ' $\tau$ ' is the shear yield stress, ' $\sigma_{\gamma}{ }^{\prime}$ is the yield strength.

After the tensile testing, the fractography was studied on the tensile fractured specimens using SEM equipment. Figure 17 shows the fractured images of both AA6063 and AISI304L sides of the fractured weld joints, those were fabricated through methods ' $A$ ' to ' $F$ '. The specimens with ' $A$ ' to ' $C$ ' methods show the mixed fracture and sliding behaviour of the metal. But, the specimens with methods ' $D$ ' to ' $F$ ' show the dimple rupture and also have the AA6063 debris on the AISI304L side. The ring pattern that formed during the welding can be seen in the images particularly in the methods ' $A$ ' to ' $C$ '. The plastic deformation and neck formation can be seen in the images of methods ' $E$ ' \& ' $F$ '. The chance of having dimple rupture on tensile fracture was more by the hemispherical faying surface rather than the welding with threaded surfaces.

\subsection{Microhardness Variations}

The sample of dissimilar joint shown in Figure 18 is suitable for determining the hardness across dissimilar interface [28]. The hardness was measured on both AA6063 \& AISI304L sides of the joint along with the regions like WI, TMAZ, HAZ, and base metal (BM) from the mid axis of the weld joint under $300 \mathrm{~g}$ loads. The values were obtained as shown in figure 18 along the $x \& y$ horizontal direction from the weld interface. The determined microhardness distribution values of all the experimental methods ' $A$ ' to ' $F$ ' are given in figure 19. In the figures, the weld interface line is considered as the reference line. AA6063 side has the hardness value in the range of 50-85 Hv whereas; AISI304L side has 250-350 Hv. The reason for the low hardness on the aluminium side is the soft nature of the metal. When analyzing the weld zone of the AA6063 side, the hardness nearby WI is better than that of AA6063 alloy BM except for method 'B', where the BM has a little higher value. Method ' $A$ ' (of the threaded faying surface) has a maximum hardness value nearby the WI of both AA6063 and AISI304L sides. At the same time, method 'E' (of hemispherical bowl faying surface) showed minimum hardness value nearby WI. From this research, it is 
considered, apart from the welding parameters, the faying surface modifications on the weld specimens can control the hardness property of the joints.

Figure 20 ( $a$ \& b) is the hardness analysis for joining methods along with base metal (BM), HAZ, TMAZ, WI on AA6063 \& AISI304L sides respectively. From Figure 20 (a), method 'D' has a maximum hardness nearby Wl; this is because of the hard force given by the AISI304L part during the frictional rotation as the hemispherical faying modification on the AA6063 side improved the hardening property of joining nearby WI by increasing the fine-grain boundaries. From Figure 20(b), method ' $A$ ' showed maximum hardness nearby WI followed by ' $B$ ' and ' $E$ ' methods. It is hereby identified that the hardness was not uniformly changing from WI to BM, it changes depends on the faying surface modifications.

Table 3 is the overall comparison of the performance of different experimental methods in terms of microhardness from the BM of the AISI304L region to the BM of the AA6063 region. Considering the AA6063 side, the hardness is decreasing from WI to BM of the joint. But, AISI304L side hardness is decreasing from WI region to BM region for the methods ' $A$ '\& ' $B$ ' but for the other methods, it is vice versa. On the WI side, the maximum and minimum hardness were recorded as $348 \mathrm{Hv}$ and $295 \mathrm{Hv}$ for methods 'A' and 'E' respectively. While, in WI of AA6063, a maximum of $88 \mathrm{Hv}$ recorded for method ' $\mathrm{D}$ ' and a minimum of $67 \mathrm{Hv}$ for method ' $\mathrm{B}$ '. Thermo-mechanically affected zone shows better values than the heataffected zone and the values $241 \mathrm{Hv}$ and $56 \mathrm{Hv}$ were recorded as the minimum for the heat-affected zone region of AISI304L side and AA6063 side respectively.

Table 3: Microhardness (Average value) comparison for different methods

\begin{tabular}{ccccccccc}
\hline $\begin{array}{c}\text { Experimental } \\
\text { methods }\end{array}$ & $\begin{array}{c}\text { 304L } \\
\text { BM }\end{array}$ & 304L & 304L & 304L & 6063 & 6063 & 6063 & 6063 \\
TMAZ & WI & WI & TMAZ & HAZ & BM \\
\hline 'A' & 326 & 286 & 311 & 348 & 81 & 79 & 56 & 74 \\
'B' & 348 & 300 & 335 & 329 & 67 & 66 & 61 & 74 \\
'C' & 295 & 266 & 286 & 328 & 79 & 72 & 63 & 59 \\
'D' & 333 & 265 & 295 & 321 & 88 & 82 & 74 & 59 \\
'E' & 312 & 280 & 296 & 295 & 72 & 64 & 58 & 66 \\
'F' & 333 & 241 & 294 & 328 & 81 & 71 & 63 & 61 \\
\hline
\end{tabular}

\subsection{Charpy V-notch Impact Test and Impact Fracture Analysis}

The impact test was done on the weld joints that were produced by the different joining methods. This test is to find out the impact toughness of the weld joints by checking their capability to observe the sudden impact loads. As told, the experimental methods were classified based on the faying surface modifications on the weld specimens. The impact energy (in Joule) recorded during Charpy testing is given in figure 21 and the fractured images of impact tested specimens are shown in figure 22 (a-f). Method ' $A$ ' showed maximum energy of $30 \mathrm{~J}$. While, the ' $B$ ' and ' $C$ ' methods with threaded on the AISI304L 
side showed a minimum of $10 \mathrm{~J}$ and $12 \mathrm{~J}$ respectively. This means that the threaded is not giving ductile formation on the joints during testing. But fortunately, all the hemispherical bowled faying modifications showed good impact energy absorption especially method ' $E$ ' which gained $26 \mathrm{~J}$ energy. From figure 22, method 'A' (figure 22(a)) showed a mixed brittle and ductile fracture, but ' $B$ ' (figure 22(b)) and ' $C$ ' (figure 22(c)) methods showed only the brittleness formed during the testing. The incomplete ring pattern formed during FW is seen in image 22(b), which showed insufficient bonding between AA6063 and AISI304L specimens by the method ' $B$ '. Figures $22(d-f)$ is belonging to the hemispherical bowl faying surfaces on the specimens. The shape of the hemispherical bowl faying surface is seen in figure 22(d) and 22(e), but it is not seen in figure 22(f) in which AA6063 and AISI304L both faying surfaces had a hemispherical bowl. From image 22(e), the method 'E' has a ring pattern in its core as it has the hemispherical bowl surface on its AISI304L side. It is mentioned that the faying modifications on the weld specimens can influence the toughness property of the weld joints.

The impact tested specimens were further studied for their fracture behaviour. The fractured SEM images are shown separately for AA6063 and AISI304L sides for different experimental methods in figure 23 . Impact pendulum struck on the V-notch. Though method ' $A$ ' (figure 22(a)) has sliding nature on the AA6063 side, the aluminium 6063 debris was sticking on the AISI304L side. Method ' $\mathrm{B}$ ' and ' $\mathrm{C}$ ' show the brittle fracture on both AA6063 and AISI304L sides. In method 'D', the ductile formation was seen on both sides and the mixed fracture has also been seen in the images. But the methods ' $E$ ' and ' $F$ ' show the dimple fracture since it tried hard against the fracture with the help of formed ductility. It improved the toughness property of the joint. Thus it is described the excellence of different faying surface on the impact toughness. The nature of the metals on which the faying surfaces made in the dissimilar welds is also to be considered during the specimen desing in FW.

\section{Conclusions}

In this study, AISI304L \& AA6063 materials were successfully joined through the RFW machine with the hemispherical bowl and threaded faying surface modifications on the weld specimens. The effectiveness of the experimental methods and the weld joints were investigated through various characterization methods and the following conclusions may be drawn:

- The axial shortening of the dissimilar joints by the methods was less than $30 \mathrm{~mm}$, which is within the limit compared to the length of weld. Method 'E' recorded the maximum value as it has the hemispherical bowl shape on its AISI304L specimen.

- From the macrographs, no defects were found in WI and the modifications in faying surfaces improved the bonding of metals. Microstructures showed good bonding between the base metals and the presence of eutectic articles in the AA6063 base side and austenitic grains with carbide precipitates on the AISI304L side.

- The U-shaped WI was formed in the joint by method 'E' and threaded WI was found in the joint made by method 'B'. The thickness of WI was a maximum of $41 \mu \mathrm{m}$. Thus the size and shape of the WI was influenced by the faying surfaces. 
- EDS analysis showed clearly the formation of some of the intermetallic layer constituted of FeAl, $\mathrm{Fe}_{3} \mathrm{Al}$ phases at the interface and the element ' $\mathrm{O}$ ' was present in the Al-rich $\mathrm{Wl}$ and the weld zone of the AA6063 side.

- From the mechanical study, though the faying modifications on the AA6063 part were not improving the strength, it stimulated the bonding, solidification and showed better hardness. The threaded modifications reduced the elongation. The experimental methods having hemispherical bowl faying surfaces, especially ' $E$ ' and ' $F$ ' showed better results in tensile properties; but, in the case of hardness, threaded faying surfaces shows better result than the hemispherical bowl with maximum of $348 \mathrm{Hv}$. A maximum of $238 \mathrm{MPa}$ tensile strength and 1.4 strain hardening rate was obtained.

- All the joints had almost equal to or more than $100 \%$ joint efficiency. The tensile strength of the AISI304L/AA6063 bimetal joint showed higher tensile values compared to AA6063 base metal with a maximum of $116 \%$ joint efficiency. The bonding area was increased as the hemispherical bowl shape faying surface has U-shaped WI. Thus it increases its joint efficieny.

- Maximum impact toughness was obtained for method 'A' having threaded face on Aa6063 side, and the hardness in the vicinity of WI was higher than that of AISI304L and AA6063 base metals.

- The fracture study showed the dimple rupture for method ' $E$ ' and ' $F$ ' and mixed fracture for ' $D$ ' and brittle fracture with sliding for methods ' $A$ ' and ' $B$ '. The hemispherical bowl faying surface on the weld specimen is good and developed more dimples in a congested manner.

\section{Declarations}

Funding: This study was not funded by any organisation.

Conflicts of interest/Competing interests: The authors declare that they have no conflict of interest.

Availability of data and material: All data and materials support their published claims and comply with field standards.

Ethics approval: Not applicable

Consent to participate: Not applicable

Consent for publication: Not applicable

Code availability: Not applicable

Authors' contributions: Experiment, testing, and original draft preparation: Senthil Murugan Subramanian. Supervision of the research, review and editing the paper: Noorul Haq Abdul Haq, and Sathiya Paulraj.

\section{References}


1. Yashwant Chapke, Dinesh Kamble, Saoud Md. Salim Shaikh, "Friction welding of aluminium alloy 6063 with copper", E3S web of conferences, 170, 2020, Article ID: 02004. https://doi.org/10.1051/e3sconf/202017002004

2. Mohammed Asif M, Kulkarni Anup Shrikrishna, P. Sathiya, Sunkulp Goel, "The impact of heat input on the strength, toughness, microhardness, microstructure and corrosion aspects of friction welded duplex stainless steel joints", Journal of manufacturing processes, 18, 2015, 92-106. http://dx.doi.org/10.1016/j.jmapro.2015.01.004

3. U, Levin.S, Wagner. L, Heinze. C, "Orbital friction welding as an alternative process for blisk manufacturing”, Journal of materials processing technology, Vol. 215, 2015, Pages 189-192. https://doi.org/10.1016/j.jmatprotec.2014.06.019

4. Pengkang Zho, Li Fu, Dechao Zhong, "Numerical simulation of transient temperature and axial deformation during linear friction welding between TC11 and TC17 titanium alloys" Computational materials science, 92, 2014, 325-333. http://dx.doi.org/10.1016/j.commatsci.2014.05.062

5. Zhida Liang, Guoliang Qin, Peihao Geng, Fan Yang, Xiangmeng Meng, "Continuous drive friction welding of 5A33 Al alloy to AZ31B Mg alloy", Journal of Manufacturing Processes, 25, 2017 153-162, http://dx.doi.org/10.1016/j.jmapro.2016.11.004

6. Kimura, Suzuki K., Kusaka M., Kaizu K., "Effect of friction welding condition on joining phenomena and mechanical properties of friction welded joint between 6063 aluminium alloy and AISI 304 stainless steel, Journal of manufacturing processes, 26, 2017, 178-187. http://dx.doi.org/10.1016/j.jmapro.2017.02.008

7. Radosław Winiczenko, "Effect of friction welding parameters on the tensile strength and microstructural properties of dissimilar AISI 1020-ASTM A536 joints", International journal of advanced manufacturing technology, 84, 2016, 941-955. DOI 10.1007/s00170-015-7751-5

8. Masoud Salamati, Mahdi Soltanpour, Ali Fazli, "Processing and tooling considerations in joining by forming technologies; part B-friction-based welding", International Journal of Advanced Manufacturing Technology, 106, 2020, 4023-408, https://doi.org/10.1007/s00170-019-04845-1

9. Gulam Mohammed Sayeed Ahmed, Ali Algahtani, Essam R. I. Mahmoud, Irfan Anjum Badruddin, "Experimental Evaluation of Interfacial Surface Cracks in Friction Welded Dissimilar Metals through Image Segmentation Technique (IST)", Materials, MDPI, 11, 2018, ID: 2460. doi:10.3390/ma11122460

10. Yanni Wei, and Fu Sun, "Microstructures and Mechanical Properties of Al/Fe and Cu/Fe Joints by Continuous Drive Friction Welding", Advances in Materials Science and Engineering, 2018, Article ID 2809356, 8 pages, 2018. https://doi.org/10.1155/2018/2809356

11. Gawhar Ibraheem Khidhir, Sherko A. Baban, "Efficiency of dissimilar friction welded 1045 medium carbon steel and 316L austenitic stainless steel joints", Mater. res. technol, 8(2), 2019, 1926-1932, https://doi.org/10.1016/j.jmrt.2019.01.010

12. Xizhang Chen, Arvind Singh, Sergey Konovalov, Juergen R. Hirsch, and KaiWang "Corrosion of Materials after Advanced Surface Processing, Joining, and Welding", International Journal of 
Corrosion, vol. 2018, Article ID 3569282, 3 pages, 2018. https://doi.org/10.1155/2018/3569282

13. Akram, J., Kalvala, P.R., Chalavadi, P. Mishra M.“Dissimilar Metal Weld Joints of P91/Ni Alloy: Microstructural Characterization of HAZ of P91 and Stress Analysis at the Weld Interfaces”, Journal of Mater. Eng. and Perform, 27, 2018, 4115-4128. https://doi.org/10.1007/s11665-018-3502-8

14. N. Prasanthi, C. Sudha, Ravikirana, S. Saroja, N. Naveen Kumar, G.D. JanakiRam, Friction welding of mild steel and titanium: Optimization of process parameters and evolution of interface microstructure, Materials \& Design, Vol. 88, 2015, 58-68. https://doi.org/10.1016/j.matdes.2015.08.141

15. G.Prashanth, R.Damodaram, S.Scudino, Z.Wang, K.Prasad Rao, J.Eckert, “Friction welding of Al-12Si parts produced by selective laser melting", Materials \& Design, Vol. 57, 2014, 632-637. https://doi.org/10.1016/j.matdes.2014.01.026

16. Marlon A. Pinheiro, and Alexandre Q. Bracarense, “Influence of Initial Contact Geometry on Mechanical Properties in Friction Welding of Dissimilar Materials Aluminum 6351 T6 and SAE 1020 Steel”, Advances in Materials Science and Engineering, vol. 2019, Article ID 1759484, 7 pages, 2019. https://doi.org/10.1155/2019/1759484

17. Senthil Murugan S., Noorul Haq A, \& Sathiya P, “Effect of welding parameters on the microstructure and mechanical properties of the friction-welded dissimilar joints of AA6063 alloy and faying surface-tapered AISI304L alloy", Welding in the World, 64, 2020, 483-499.

https://doi.org/10.1007/s40194-020-00846-x

18. Hardik Vyas, Kush P. Mehta, Vishvesh Badheka, Bharat Doshi, "Pipe-to-pipe friction welding of dissimilar Al-SS joints for cryogenic applications", Journal of the Brazilian Society of Mechanical Sciences and Engineering, 42:96, https://doi.org/10.1007/s40430-020-2181-1

19. Jibrin Sule, Supriyo Ganguly, Wojciech Suder, Thilo Pirling, “Effect of high-pressure rolling followed by laser processing on mechanical properties, microstructure and residual stress distribution in multipass welds of 304L stainless steel”, Inter. J. Adv Manuf Technol, 86, 2016, 2127-2138, DOI 10.1007/s00170-015-8299-0

20. Radosław Winiczenko, Mieczysław Kaczorowski, Andrzej Skibicki, "The microstructures, mechanical properties, and temperature distributions in nodular cast iron friction-welded joint", Journal of the Brazilian Society of Mechanical Sciences and Engineering, 40:347, 2018. https://doi.org/10.1007/s40430-018-1261-y

21. Kumar R, Balasubramanian M, “Experimental investigation of Tie6Ale4V titanium alloy and 304L stainless steel friction welded with copper interlayer", Defence Technology, 11, 2015, 65-75. https://doi.org/10.1016/j.dt.2014.10.001

22. Radosław WINICZENKO, Robert SALAT, Michał AWTONIUK, "Estimation of tensile strength of ductile iron friction welded joints using hybrid intelligent methods, Transactions of Nonferrous Metals Society of China, Vol. 23, Issue 2, 2013, 385-391, https://doi.org/10.1016/S1003-6326(13)62474-7

23. Tavio, Retno Anggraini, I. Gede Putu Raka, and Agustiar, "Tensile strength/yield strength (TS/YS) ratios of high-strength steel (HSS) reinforcing bars”, AIP Conference Proceedings, 1964, 020036, 
2018. https://doi.org/10.1063/1.5038318

24. Sivakumaran K S, "Role of yield-to-tensile strength ratio in the design of steel structures", Niobium Bearing Structural Steels, TMS (The Minerals, Metals \& Materials Society), 2010.

25. Senthil, M.S., Noorul, H.A., Sathiya, P., "Eco-friendly frictional joining of AA6063 and AISI304L dissimilar metals and characterisation of bimetal joints", Journal of New Materials for Electrochemical Systems", Vol. 23, No. 2, 2020, 101-111. https://doi.org/10.14447/jnmes.v23i2.a07

26. Senthil Murugan S, Sathiya P \& Noorul Haq A "Experimental study on the effect of silver, nickel and chromium interlayers and upset pressure in joining SS304L-AA6063 alloys through direct drive friction welding process", J Braz. Soc. Mech. Sci. Eng., 42, 611, 2020.

https://doi.org/10.1007/s40430-020-02687-7

27. Zhang P, Li S.X., Z.F. Zhang, "General relationship between strength and hardness", Materials Science and Engineering A, 529, 2011, 62-73. doi:1016/j.msea.2011.08.061

28. Kaczorowski, M.and Winiczenko, R. "The microstructure and mass transport during friction welding of ductile cast iron", Industrial Lubrication and Tribology, Vol. 65 No. 4, 2013, 251258. https://doi.org/10.1108/00368791311331248

\section{Figures}
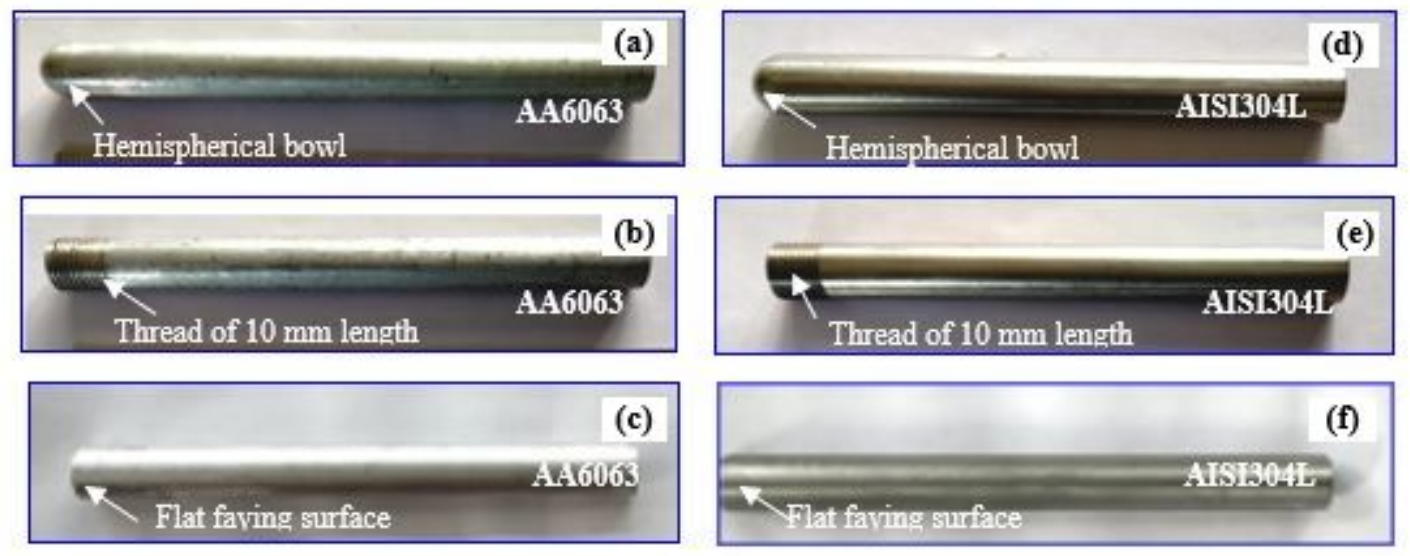

\section{Figure 1}

(a-f): Flat, hemispherical bowl, and threaded faying surfaces on weld specimens (of size $100 \mathrm{~mm}$ length and $\phi 12 \mathrm{~mm}$ diameter) 


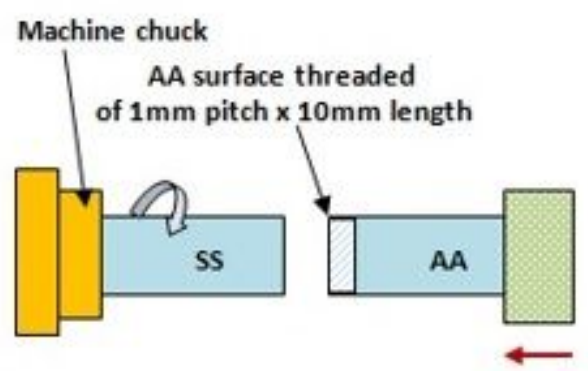

Method 'A'

Machine chuck

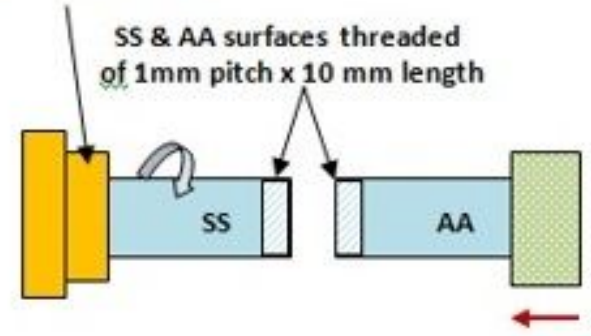

Method ' $C$ '

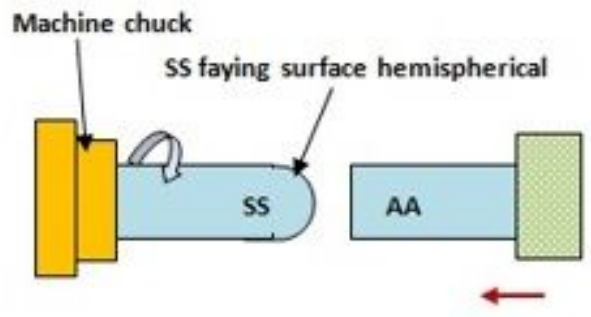

Method 'E'

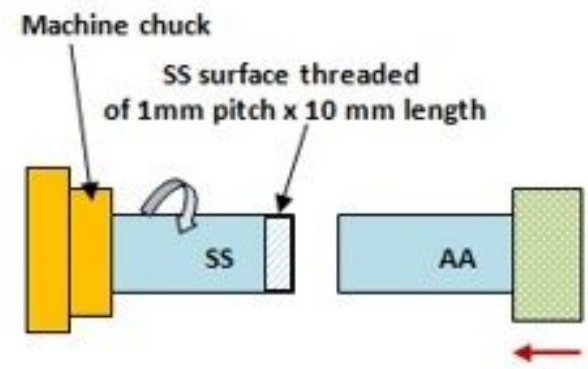

Method 'B'

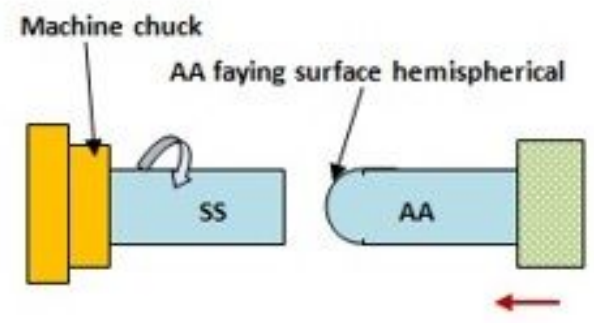

Method ' $D$ '

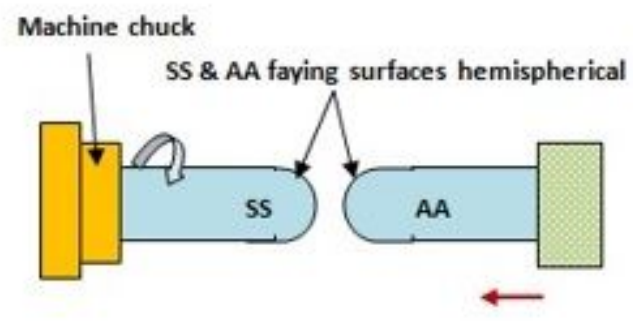

Method ' $F$ '

Figure 2

Experimental methods (A to F) for the joining with different faying surface modifications, where SS AISI304L alloy and AA-AA6063 alloy

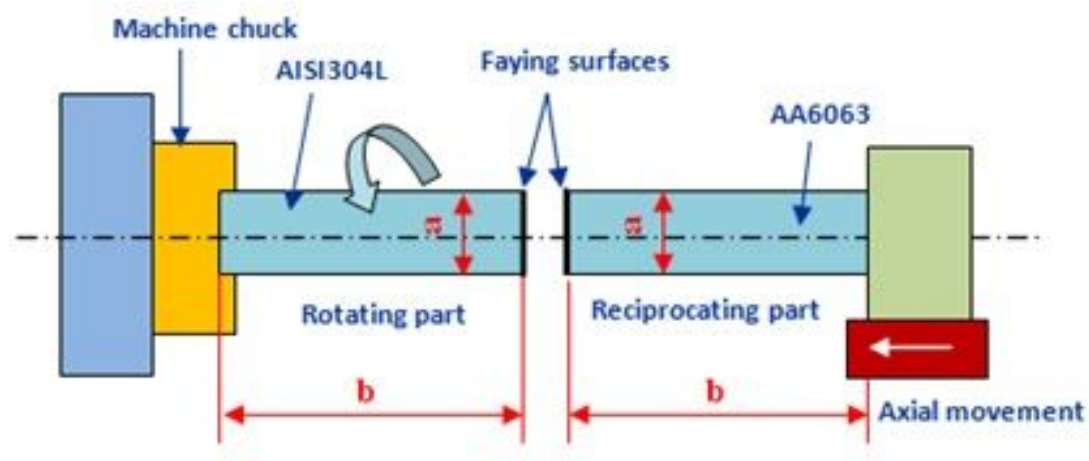

Figure 3 
Rotary friction welding process followed in this study (where, $a=\$ 12 \mathrm{~mm}, \mathrm{~b}=100 \mathrm{~mm}$ )
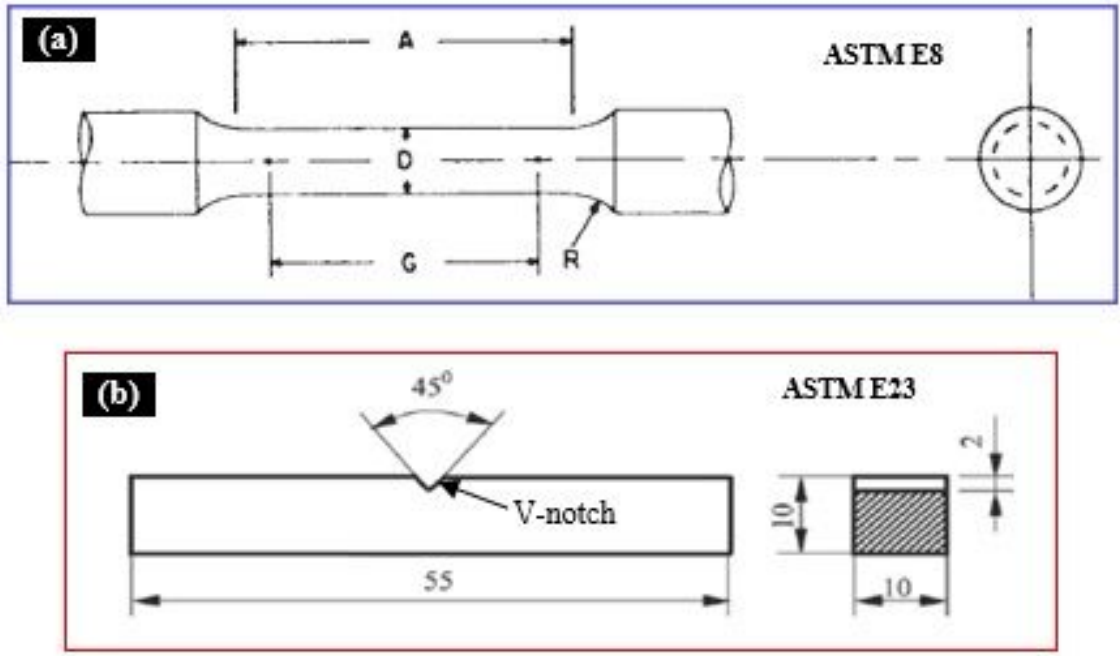

Figure 4

(a, b): Sample preparation as per ASTM standard dimension (in ' $m m^{\prime}$ ) for (a) tensile, where, D-9 dia., G-45, A-54, R-8, \& (b) impact testing
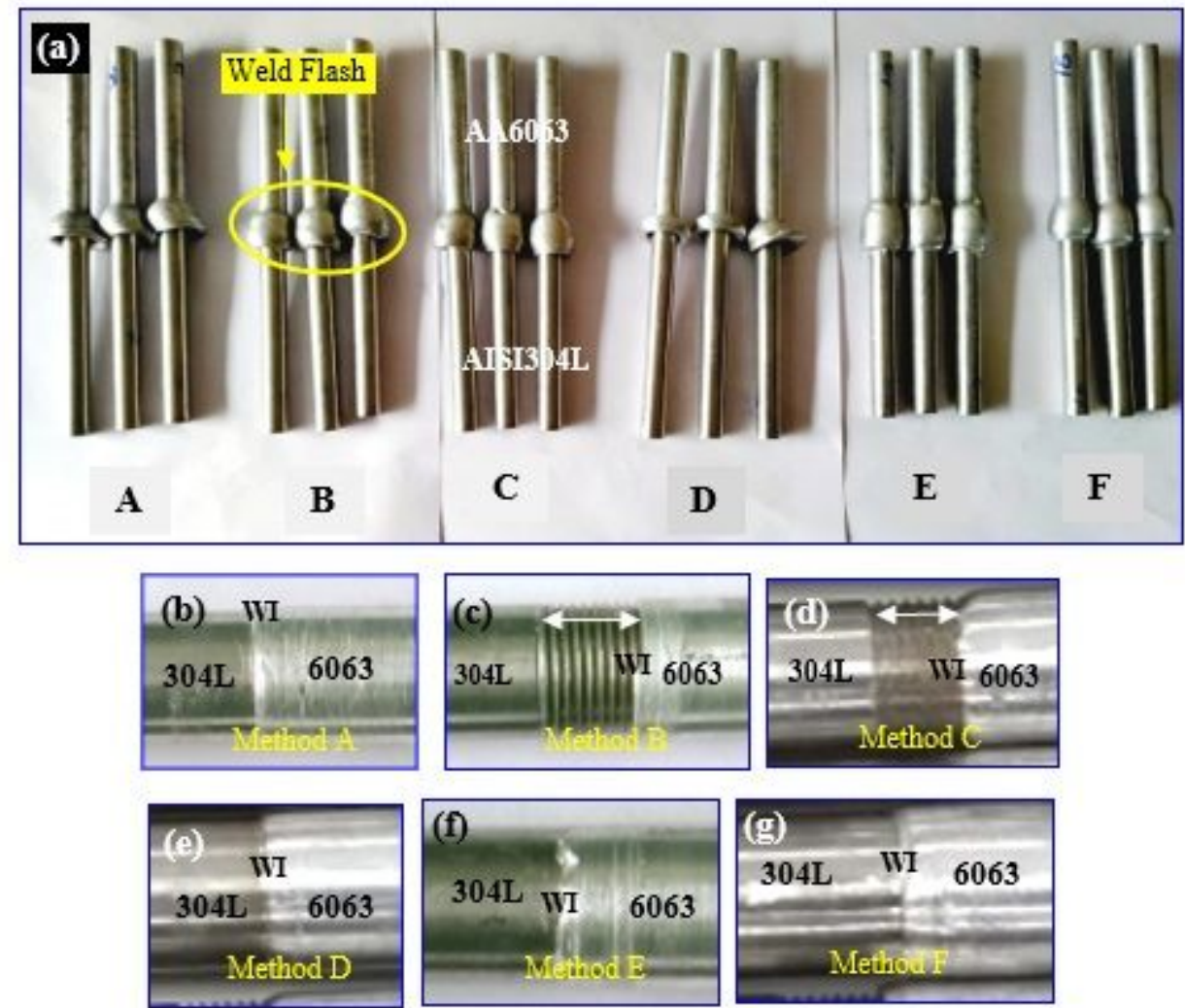

\section{Figure 5}

(a-g): (a) Friction welded bimetal joints fabricated through the methods 'A' to ' $F$ '; and (b-g) the weld joint zones are shown for the different joints 

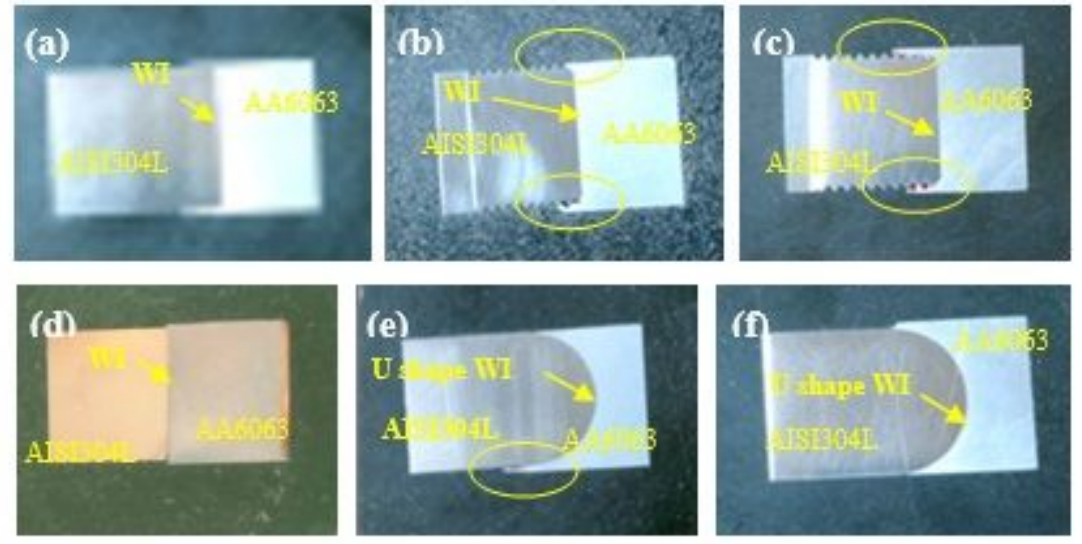

Figure 6

(a-f): Weld interface (WI) (of height $12 \mathrm{~mm}$ ) of FW specimens prepared by (a) method $\mathrm{A}$, (b) method $\mathrm{B}$, (c) method $C$, (d) method $D$, (e) method $E$, (f) method $F$

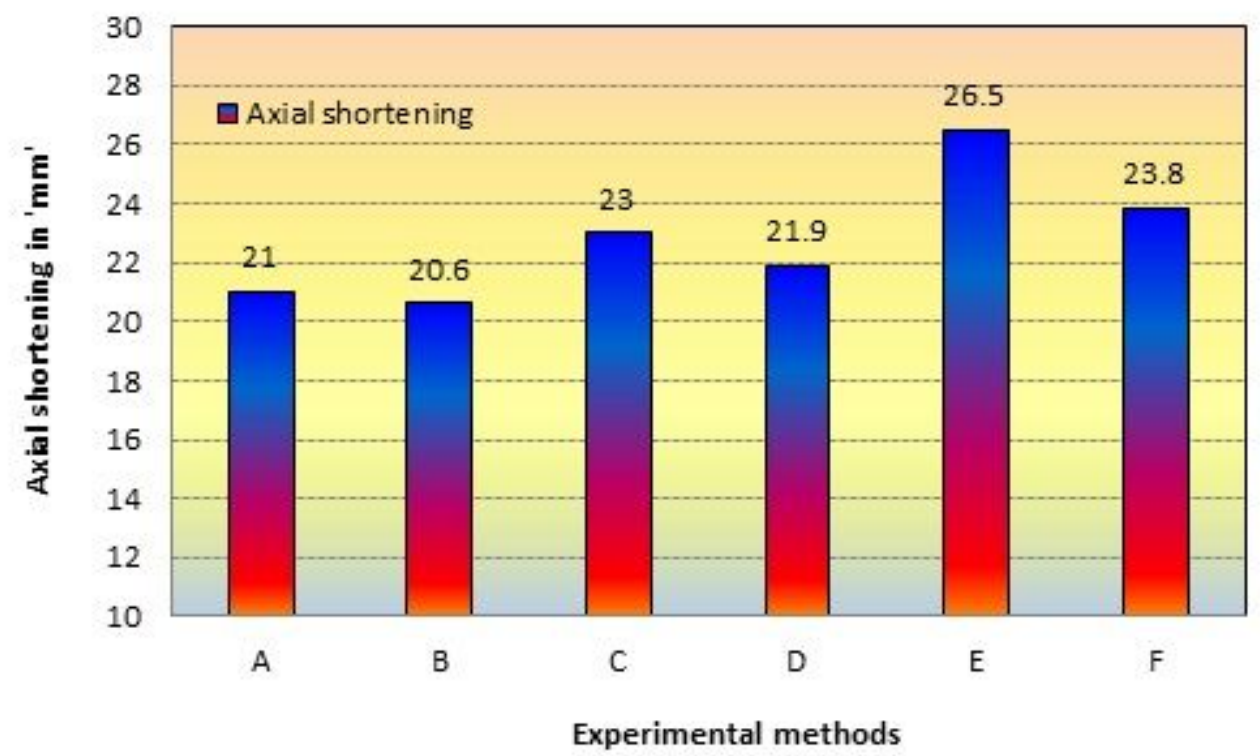

Figure 7

Axial shortening of the joints made by different experimental methods after FW 

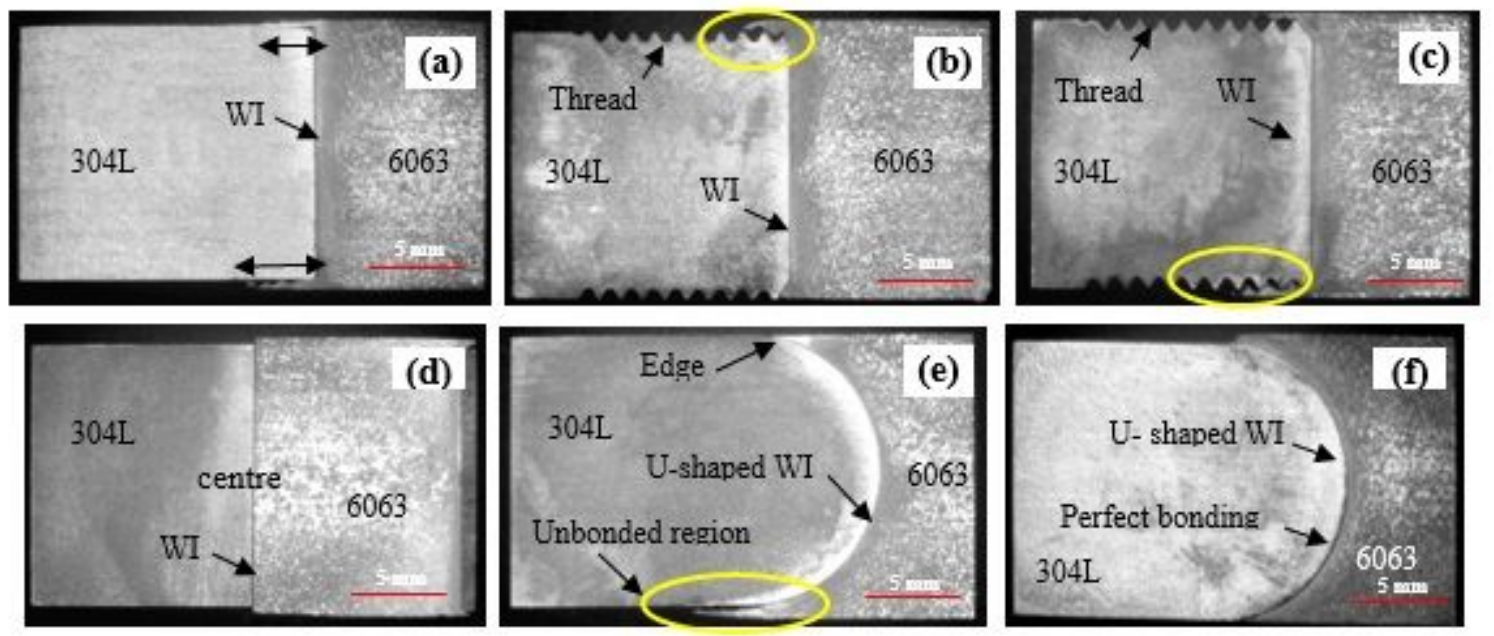

Figure 8

(a-f): Macrographs of dissimilar joints fabricated by the experimental methods: (a) A, (b) B, (c) C, (d) D, (e) E, and (f) method $F$ 

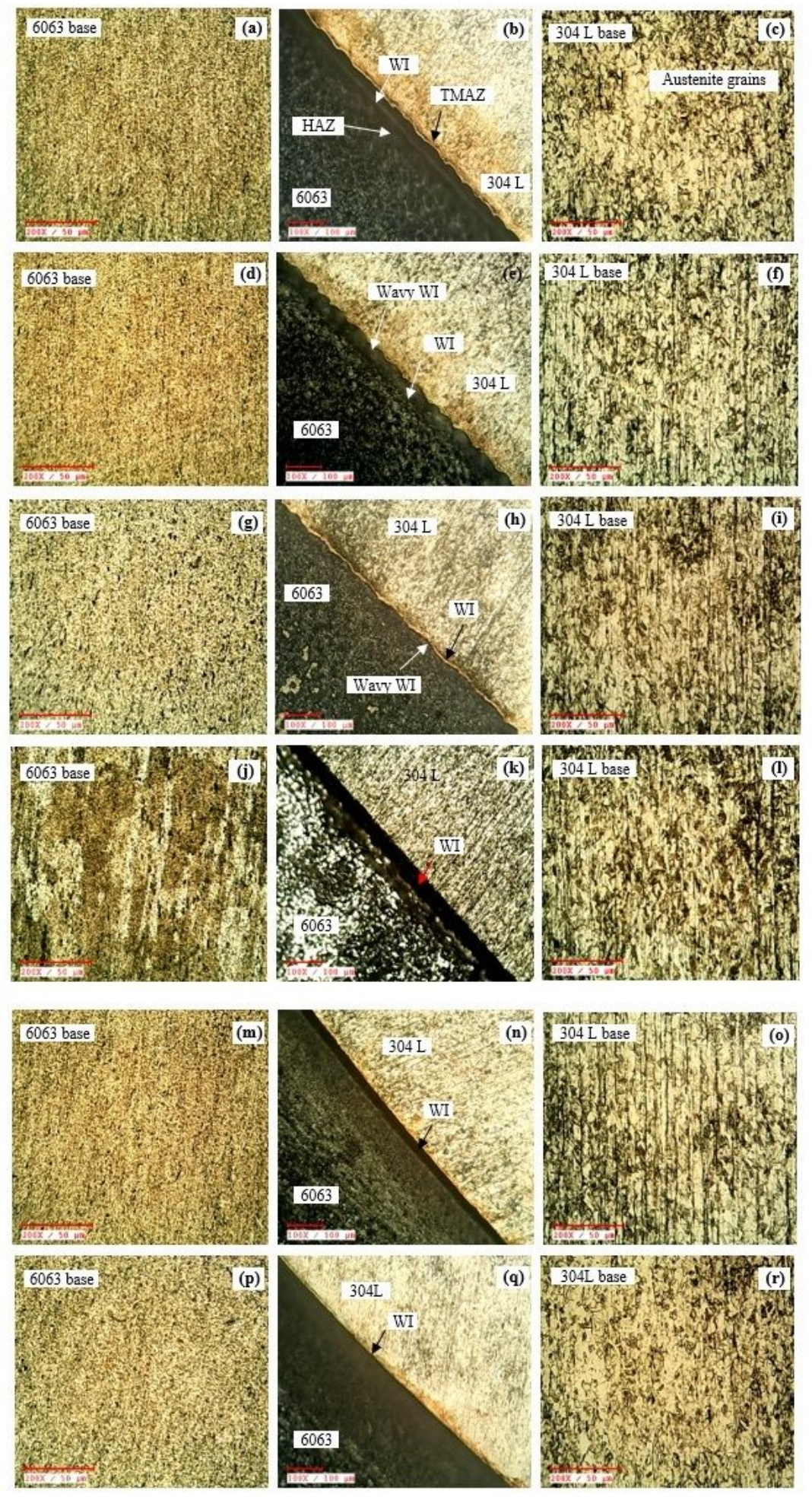

\section{Figure 9}

(a-r): Optical microstructure of the dissimilar joints fabricated by: method A (a-c), method B (d-f), method $C(g-i)$, method D (j-l), method $E(m-0)$, method $F(p-r)$ 


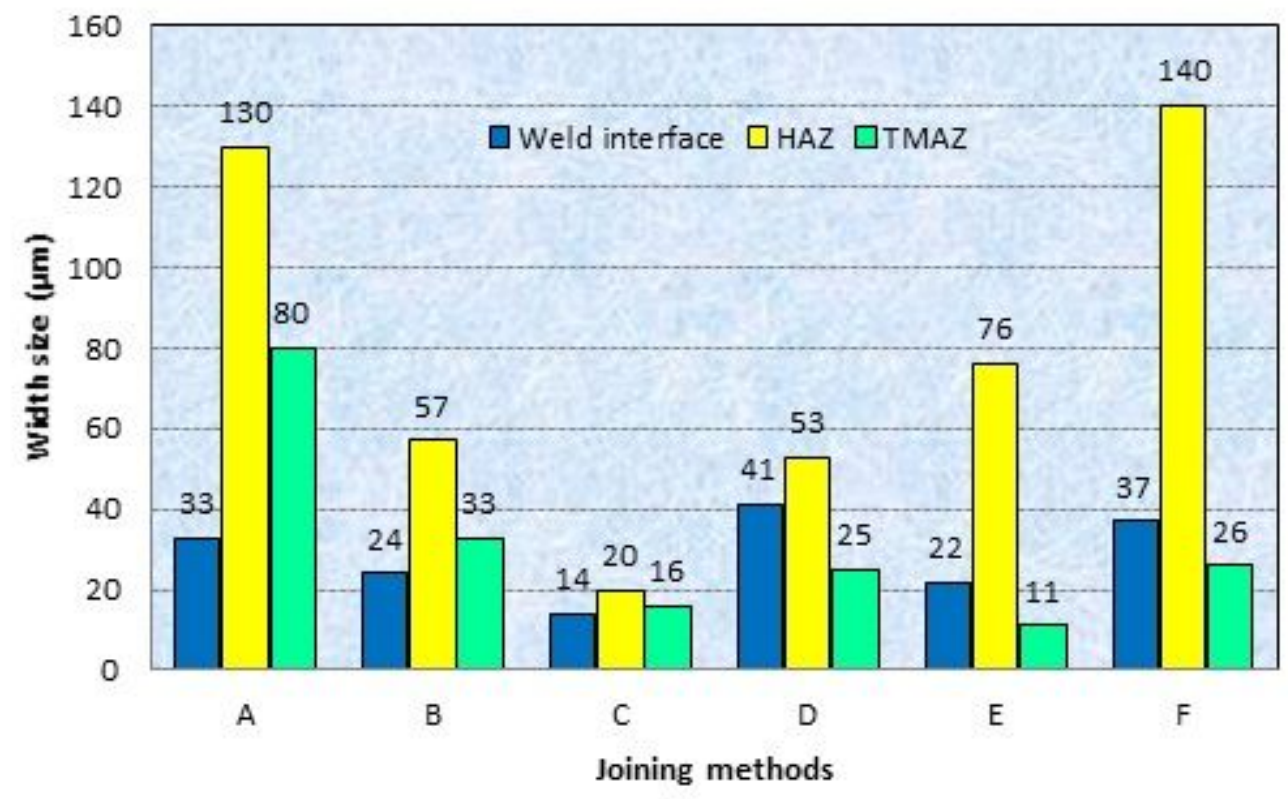

Figure 10

Width measurement in weld zones (WI, HAZ, TMAZ) for different experimental methods
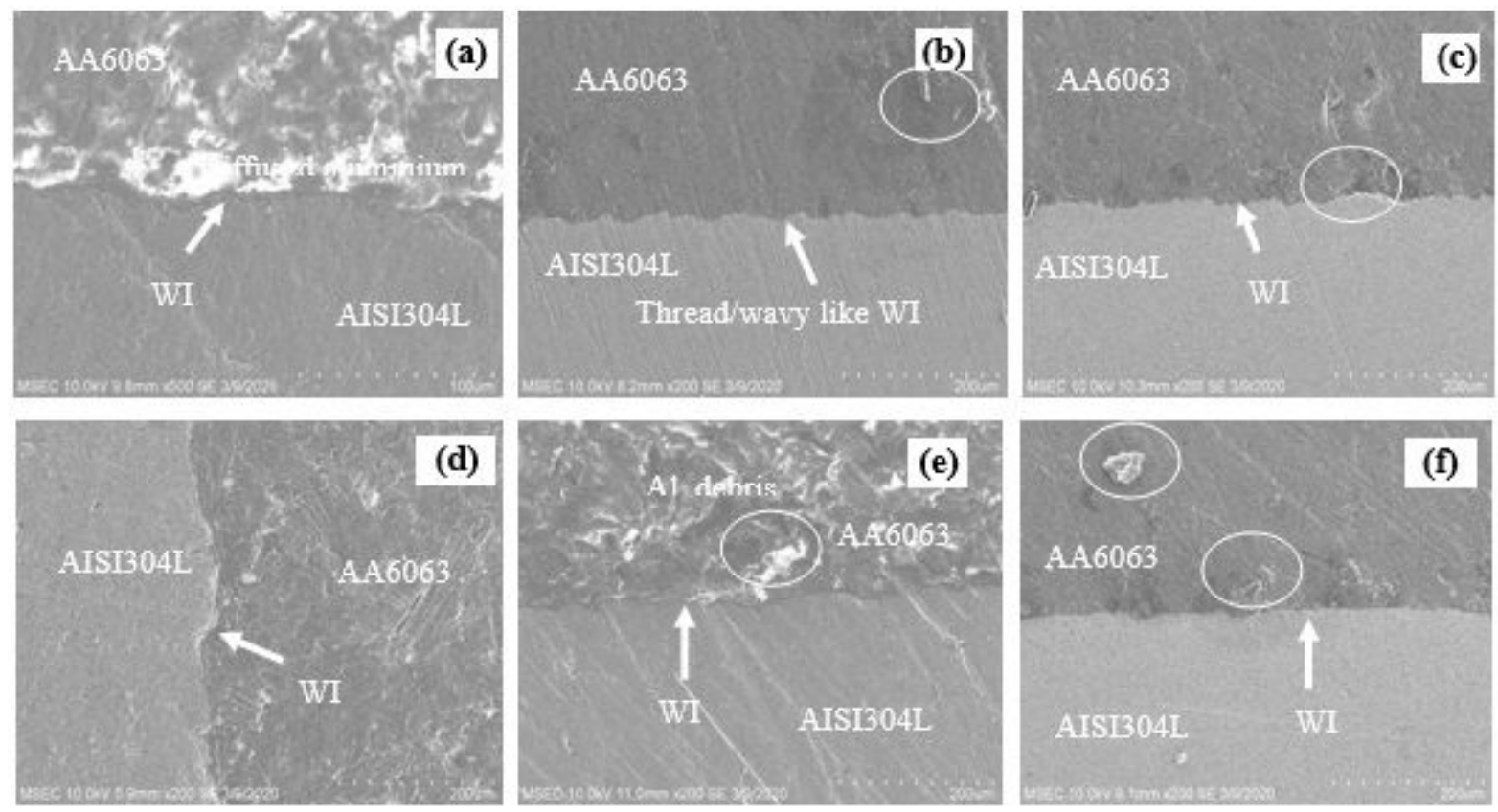

\section{Figure 11}

(a-f): SEM images of the weld interface (WI) and weld zone of dissimilar joints fabricated by: method $A$ (a), method B (b), method C (c), method D (d), method $E(e)$ and method F (f) 

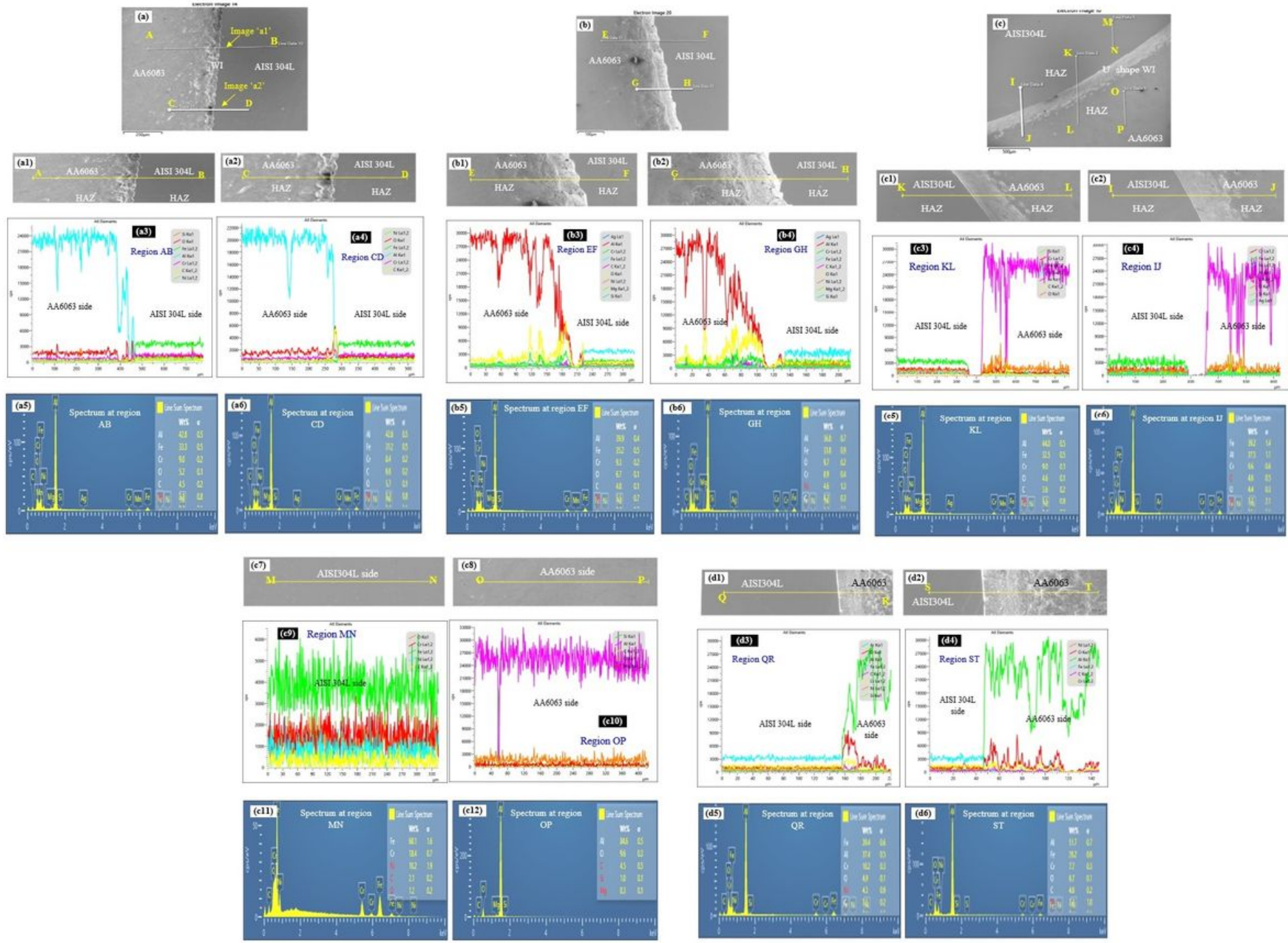

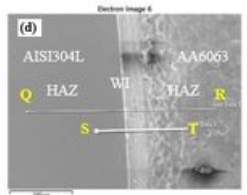

\section{Figure 12}

(a-d6): Line spectrum for the distribution of the elements along weld zones for the joints A, B, C, E and F. Where, images a, b, c, d are weld zone of joints. Images a3, a4, b3, b4, c3, c4, c9, c10, d3, d4 are the element distribution along weld zones of the joints. Images a5, a6, b5, b6, c5, c6, c11, c12, d5, d6-line EDS spectra at different regions of weld zones 

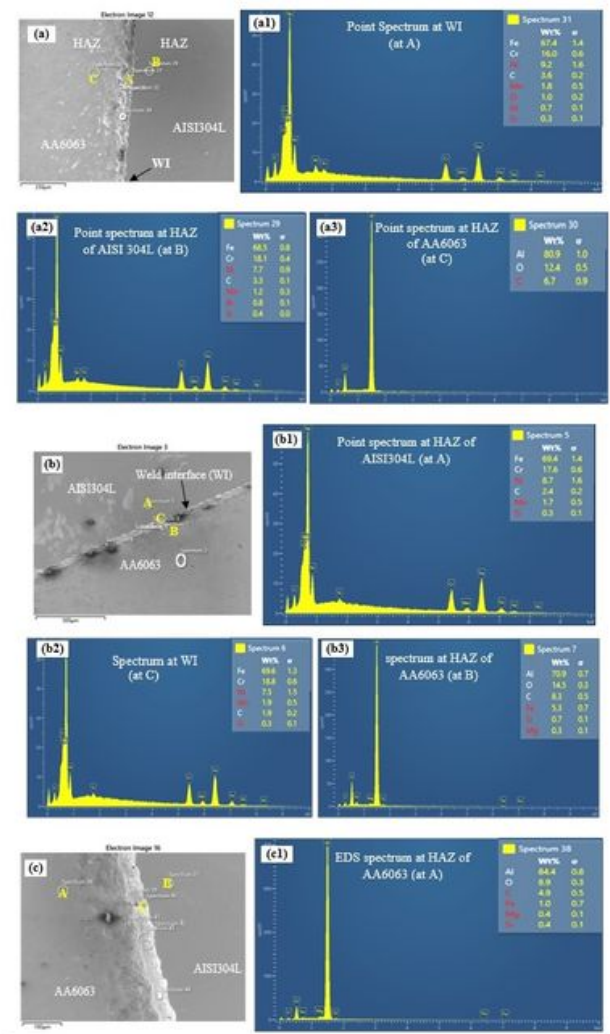
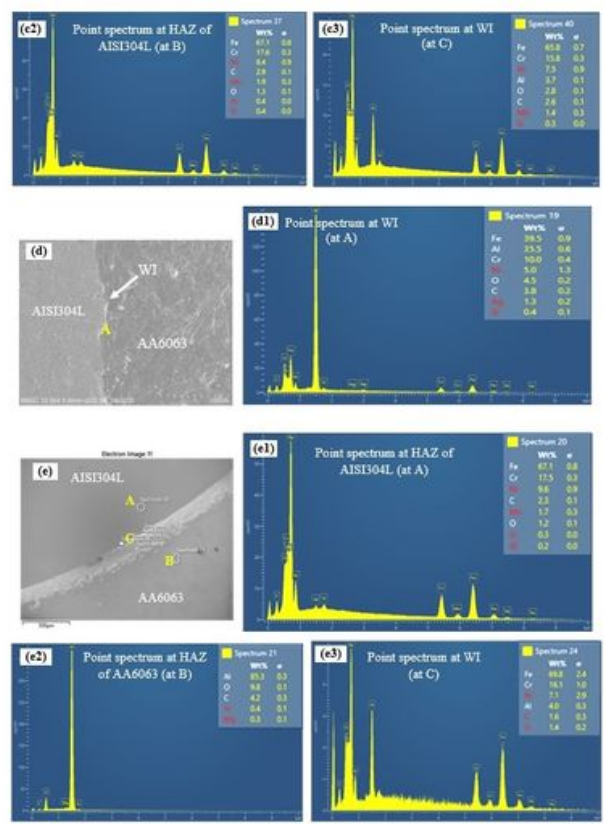
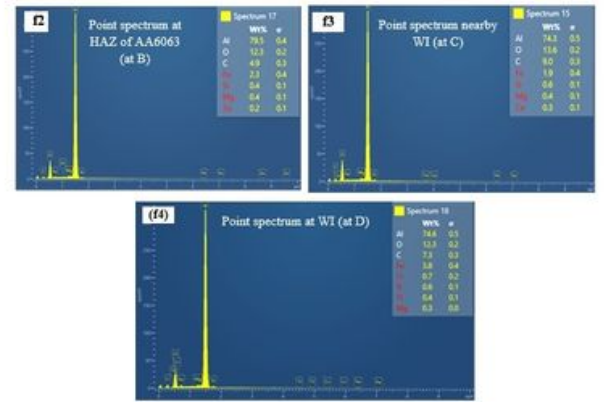

\section{Figure 13}

(a-f4): SEM of weld joint and EDS point spectrum for the methods A, B, C, D, E and F (images a, b, c, d, e and $f$ respectively) at WI, and HAZ of weld joints
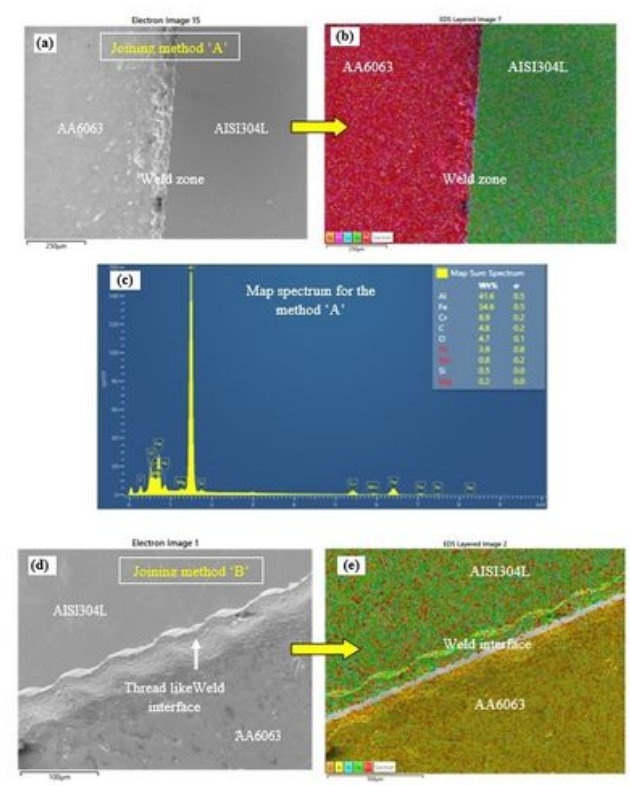
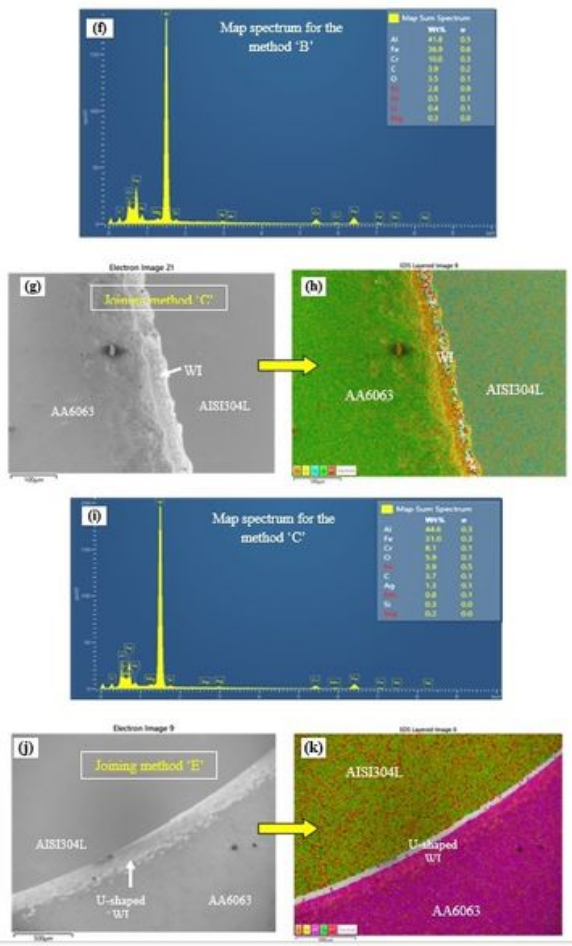
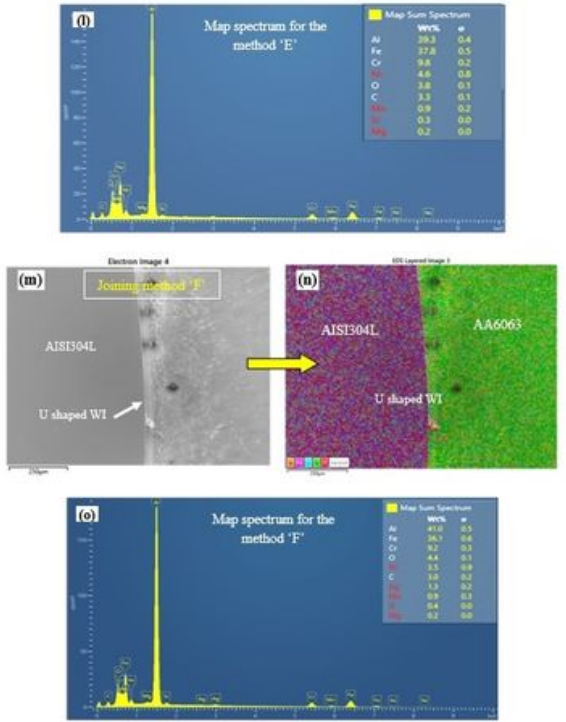
Figure 14

(a-o): Colour mapping and spectrum at the weld zones of the experimental methods A, B, C, E, and F

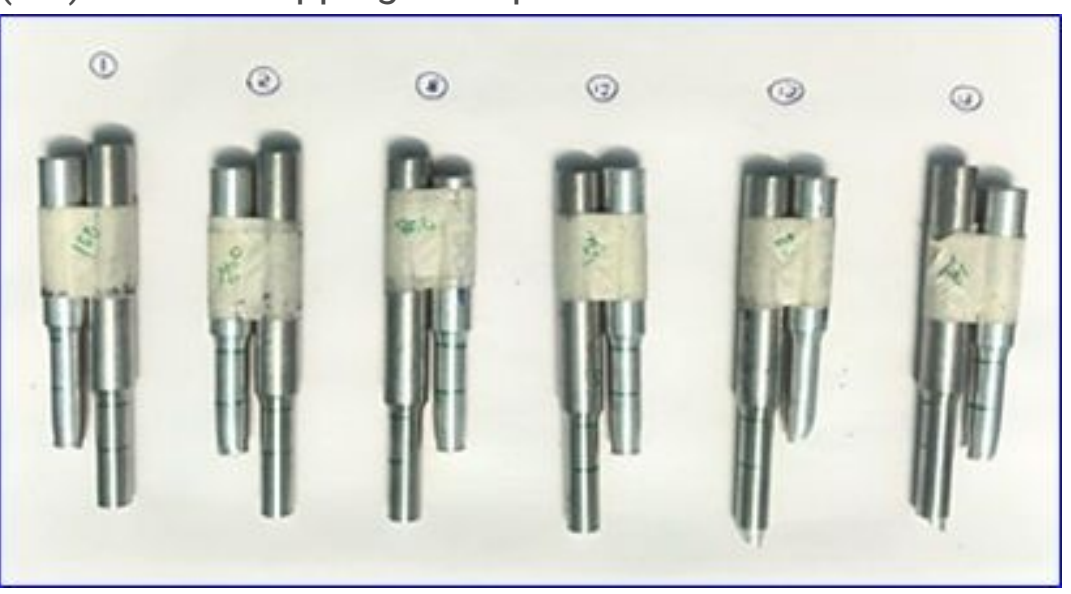

Figure 15

Broken weld joints of experimental methods ( $A$ to $F$ ) after the tensile testing 

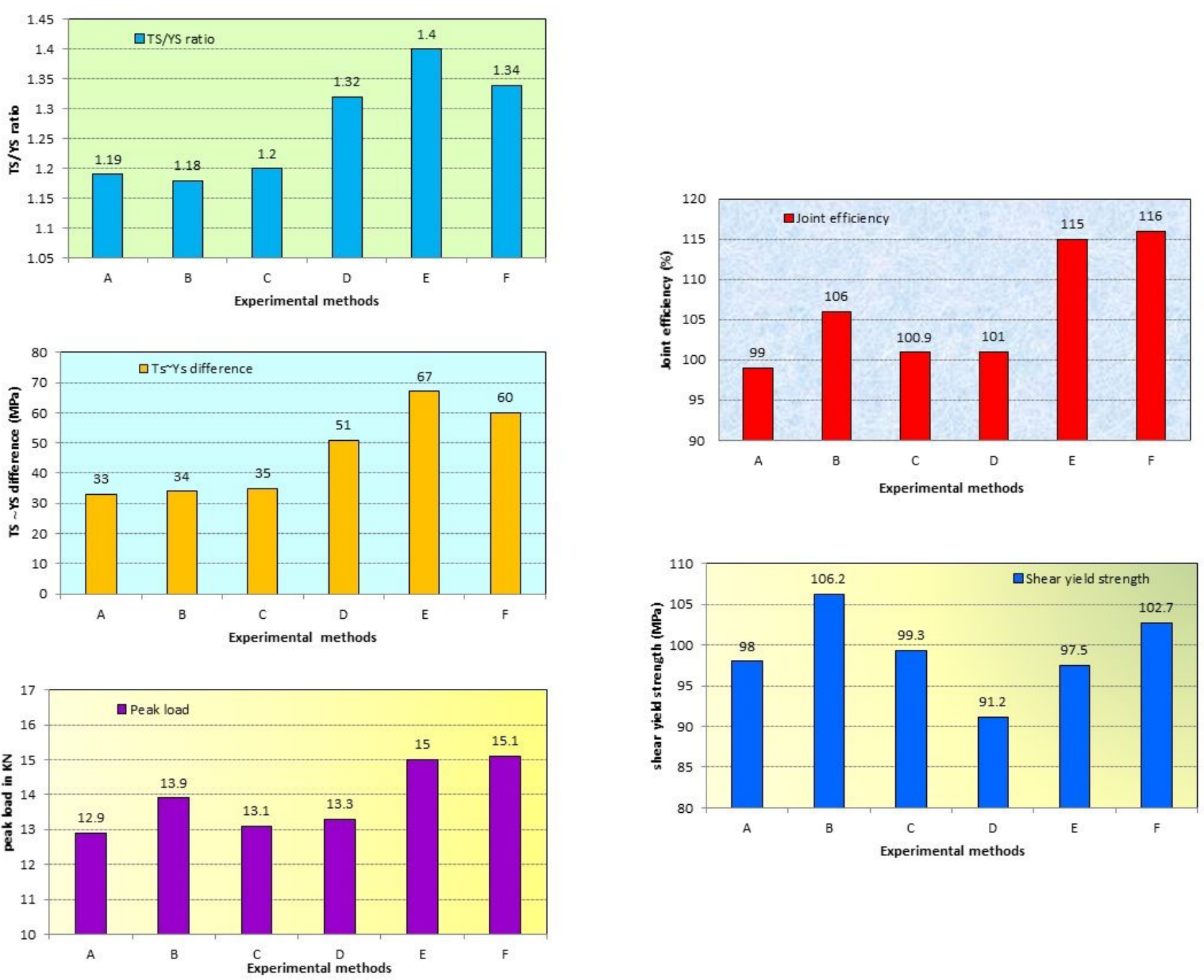

Figure 16

(a-g): Tensile properties of weld joints fabricated through the methods ' $A$ ' to ' $F$ ': (a) strength, (b) \% elongation, (c) TS/YS ratio, (d) TS YS difference, (e) peak load, (f) joint efficiency, (g) shear strength 

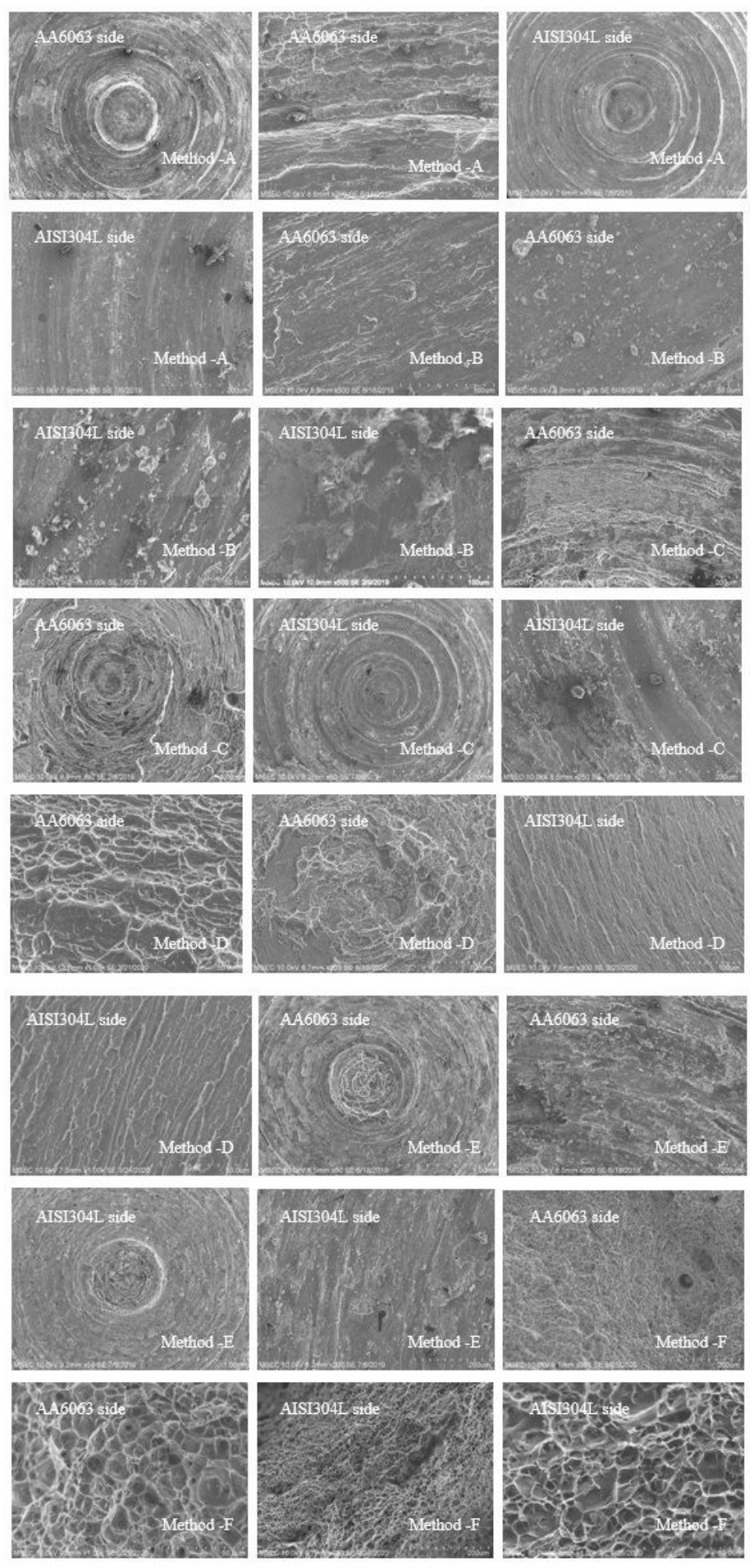

\section{Figure 17}

Tensile fracture SEM images for the methods 'A' to 'F' on both AISI304L \& AA6063 sides 


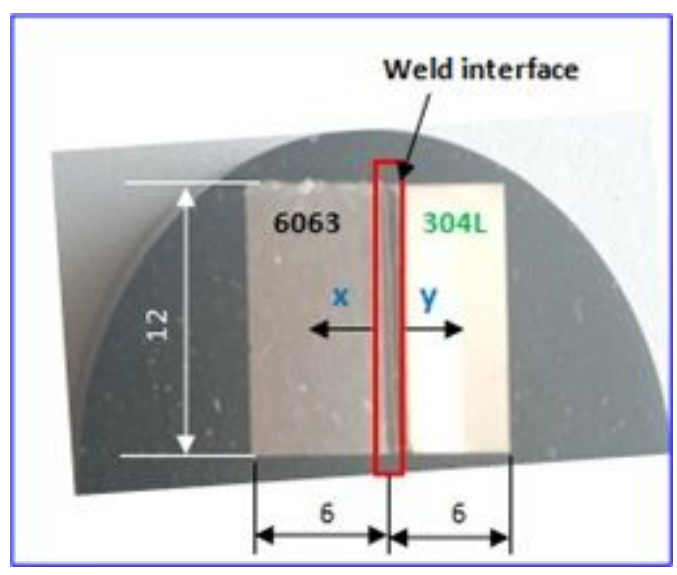

Figure 18

Sample of dissimilar joint for microhardness testing (dimensions in ' $m m^{\prime}$ ') 

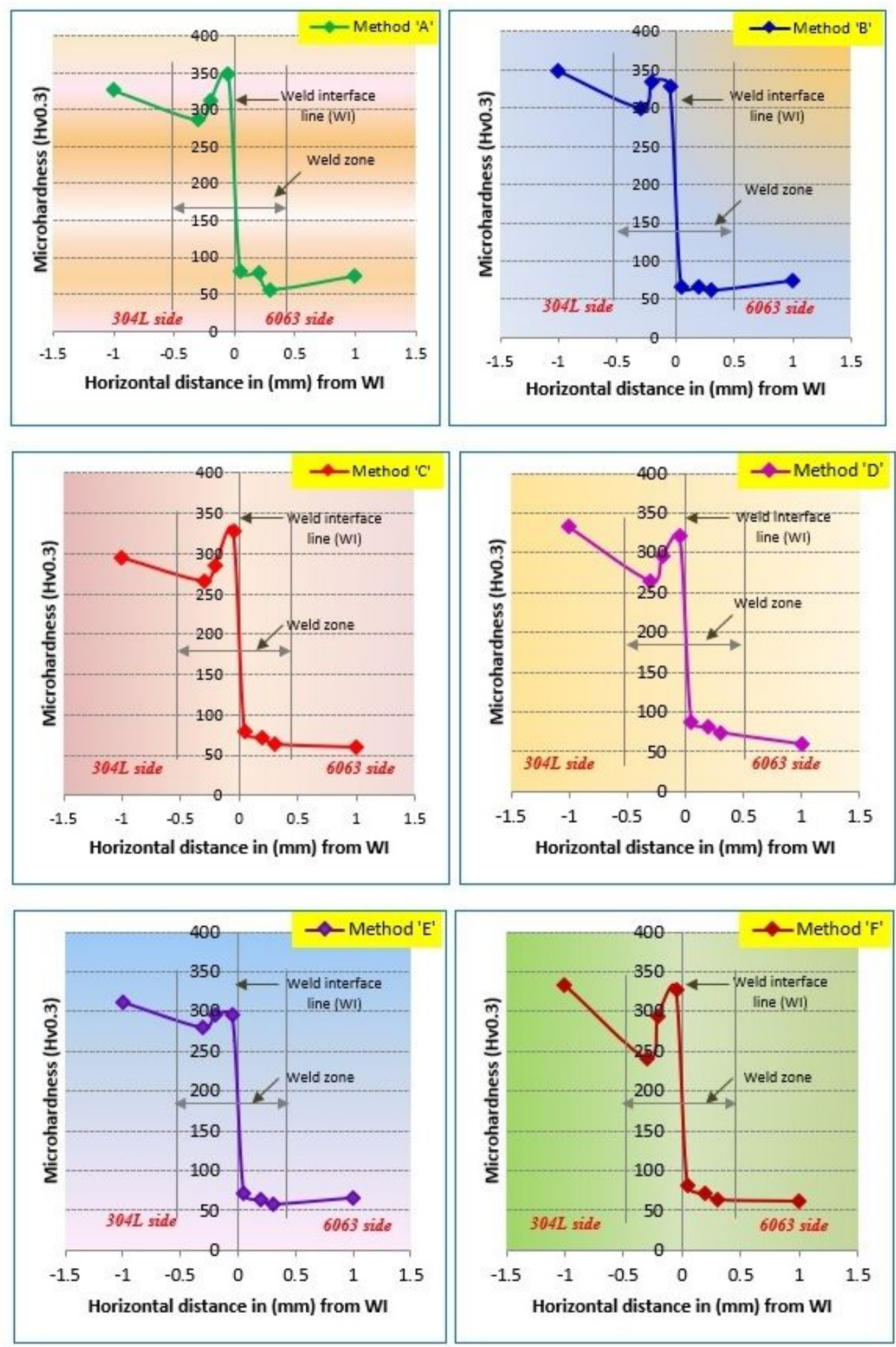

\section{Figure 19}

Vickers microhardness distribution on weld specimens for experimental methods ' $A$ ' to ' $F$ ' 

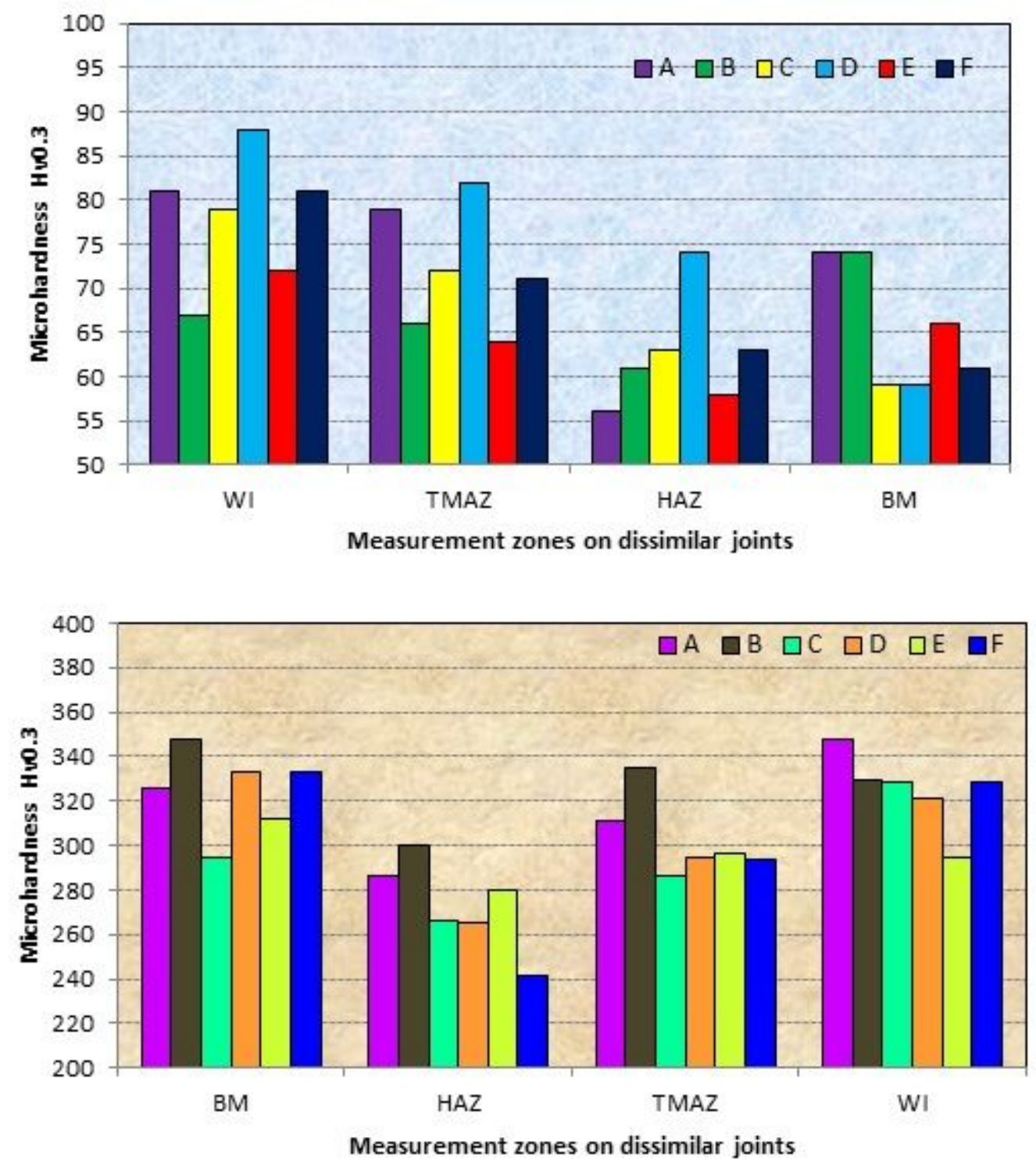

Figure 20

(a, b): Microhardness of different regions at dissimilar joint by methods 'A' to ' $F$ ': (a) AA6063 side, (b) AISI304L side 


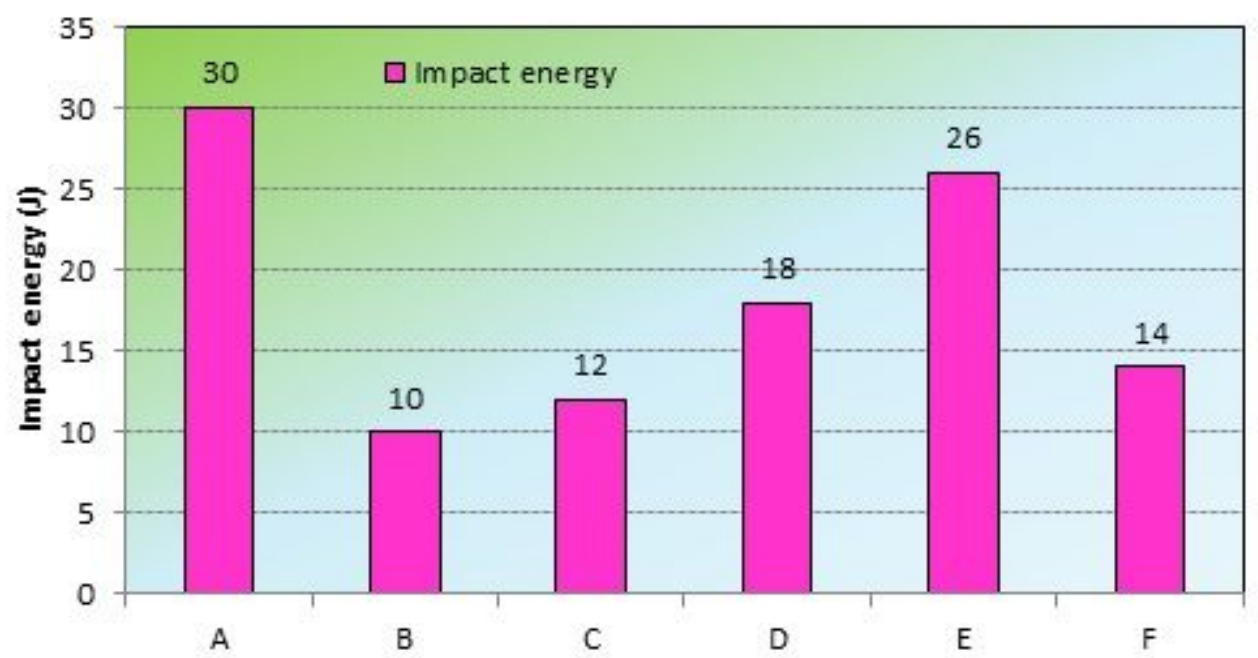

Experimental methods

\section{Figure 21}

Impact energy observed values for the experimental methods ' $\mathrm{A}$ ' to ' $\mathrm{F}$ '
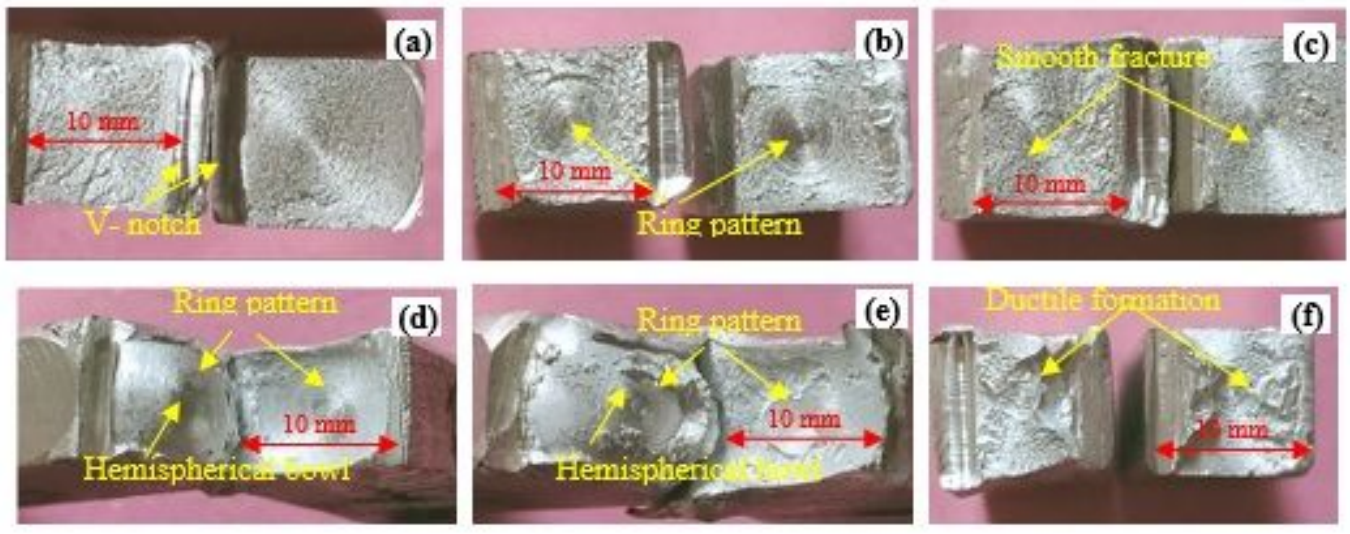

Figure 22

(a-f): Impact tested specimens' fracture images 

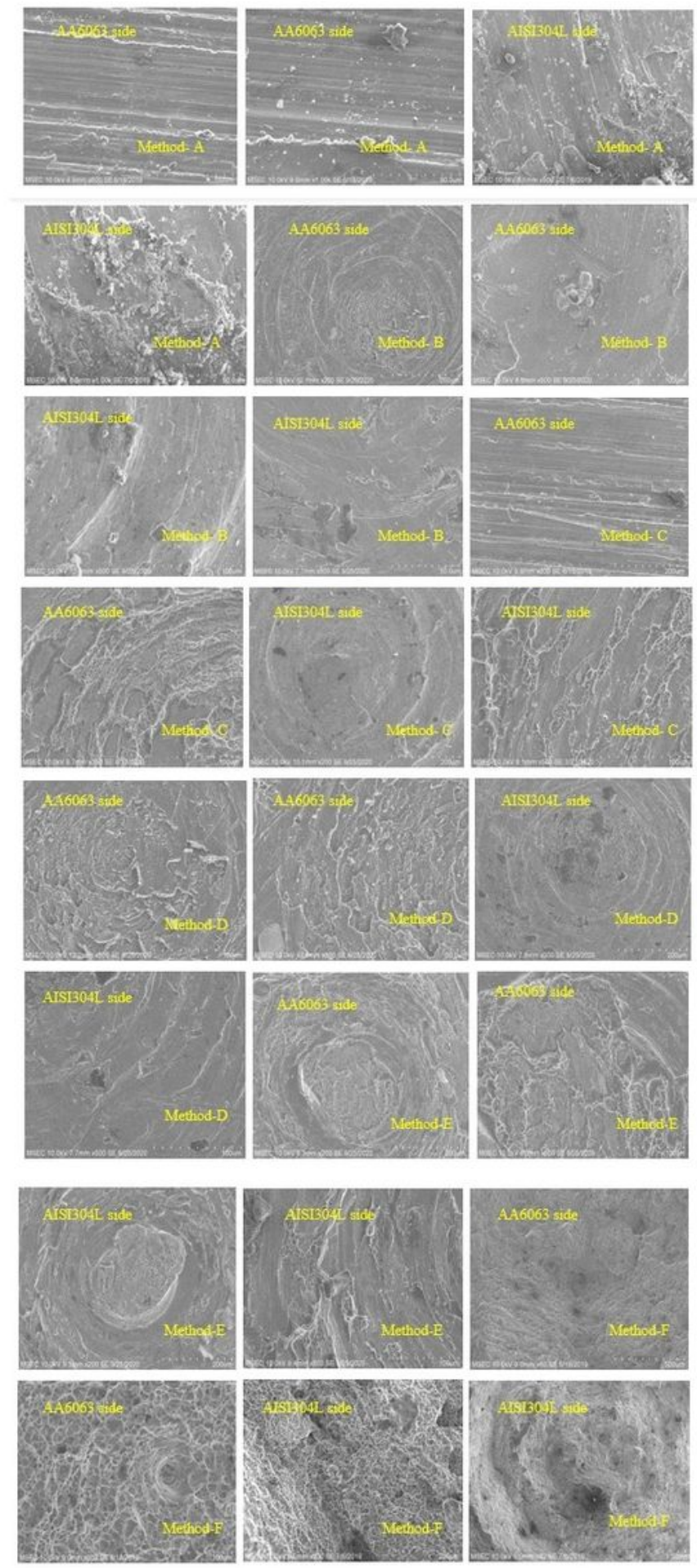

Figure 23

SEM images of impact fracture specimens of all methods on both AISI304L \& AA6063 sides 